\title{
Spatial and temporal habitat partitioning by zooplankton in the Bornholm Basin (central Baltic Sea)
}

\author{
Jan Schulz ${ }^{\text {a,b,c,* }}$, Myron A. Peck ${ }^{\mathrm{d}}$, Kristina Barz ${ }^{\mathrm{e}}$, Jörn Oliver Schmidt ${ }^{\mathrm{f}}$, Frank C. Hansen ${ }^{\mathrm{g}}$, Janna Peters ${ }^{\mathrm{h}}$, \\ Jasmin Renz ${ }^{i}$, Miriam Dickmann ${ }^{j}$, Volker Mohrholz ${ }^{k}$, Jörg Dutz ${ }^{1}$, Hans-Jürgen Hirche ${ }^{b}$ \\ a Institute for Chemistry and Biology of the Marine Environment, University of Oldenburg, Schleusenstraße 1, Wilhelmshaven, Germany \\ ${ }^{\mathrm{b}}$ Alfred Wegener Institute for Polar and Marine Research, Am alten Hafen 26, Bremerhaven, Germany \\ ${ }^{\mathrm{C}}$ Institute for Marine Resources, Bussestraße 27, Bremerhaven, Germany \\ ${ }^{\mathrm{d}}$ Institute of Hydrobiology and Fisheries Science, CEN Center for Earth System Research and Sustainability, Olbersweg 24, Hamburg, Germany \\ e Thünen Institute of Baltic Sea Fisheries, Alter Hafen Süd 2, Rostock, Germany \\ ${ }^{\mathrm{f}}$ Christian Albrechts University, Olshausenstraße 40, Kiel, Germany \\ ${ }^{\mathrm{g}}$ University of Rostock, Albert Einstein Straße 3, Rostock, Germany \\ ${ }^{\mathrm{h}}$ Institute for Hydrobiology and Fisheries Research, Große Elbstraße 133, Hamburg, Germany \\ ${ }^{i}$ Senckenberg Institute, German Centre for Marine Biodiversity Research, Martin Luther King Platz 3, Hamburg, Germany \\ ${ }^{\mathrm{j}}$ Novartis Animal Health, Munich, Germany \\ ${ }^{\mathrm{k}}$ Institute for Baltic Research, Seestraße 15, Rostock, Germany \\ ${ }^{1}$ National Institute of Aquatic Resources, Technical University of Denmark, Jaegersborg Allé 1, Charlottenlund, Denmark
}

\section{A R T I C L E I N F O}

\section{Article history:}

Available online $\mathrm{xxxx}$

\begin{abstract}
A B S T R A C T
The deep basins in the Baltic Sea such as the Bornholm Basin (BB) are subject to seasonal changes in the strength of physico-chemical stratification. These depth-related changes in key abiotic factors are strong drivers of habitat partitioning by the autochthonous zooplankton community. Species-specific ecophysiological preferences often result in both seasonal and inter-annual changes in vertical abundance that, when combined with depth-specific water currents, also lead to horizontal differences in spatial distribution. The present study documented the seasonal and depth-specific changes in the abundance and species composition of zooplankton in the BB based upon broad-scale survey data: 832 vertically-resolved $(10 \mathrm{~m})$ multinet samples collected at nine stations between March 2002 and May 2003. Changes in the zooplankton community were significantly correlated with changes in ambient hydrography. Each of five taxa (Bosmina coregoni maritima, Acartia spp., Pseudocalanus spp., Temora longicornis, Synchaeta spp.) contributed $>10 \%$ to the zooplankton community composition. The appearance of cladocerans was mainly correlated with the phenology of thermocline development in the spring. The cladoceran B. coregoni maritima was a dominant member of this community during the warmest periods, preferring the surface waters above the thermocline. Copepods exhibited distinct, ontogenetic and seasonal changes in their distribution. The rotifers (Synchaeta sp.) were the most abundant zooplankton in May. Based on a multivariate approach and the evaluation of vertical distribution patterns, five major habitat utilisation modes were identified that were based, to a large extent, on the dynamics of thermal and haline stratification of the Baltic Sea. Our statistical analysis of one of the most thorough datasets collected on Baltic zooplankton in recent decades reveals some of the factors that make this stratified system highly dynamic with respect to the spatial overlap between predators and prey. As fish and gelatinous plankton often feed in distinct layers and/or exhibit feeding migrations, the inhomogeneous distribution of potential prey can result in a spatial mismatch. Based on the five modes identified at the community level for zooplankton, we discuss how climate-driven hydrographic variability may influence the strength of trophic coupling within the Bornholm Basin.
\end{abstract}

(c) 2012 Elsevier Ltd. All rights reserved.
* Corresponding author at: Institute for Chemistry and Biology of the Marine Environment, University of Oldenburg, Schleusenstraße 1, Wilhelmshaven, Germany. Tel.: +49 44217785815 .

E-mail address: Jan.Schulz@uni-oldenburg.de (J. Schulz).

\section{Introduction}

The well-known match-mismatch theory (Cushing, 1975, 1990) and most other marine fish recruitment theories dealing with the overlap of young fish and their prey (e.g. see Houde, 2008) often consider temporal aspects but rarely spatial mismatches. Spatial match-mismatch dynamics occurring across entire regions of

0079-6611/\$ - see front matter (c) 2012 Elsevier Ltd. All rights reserved. http://dx.doi.org/10.1016/j.pocean.2012.07.002 
marine ecosystems are likely easier to detect than those occurring at smaller spatial scales. For example, match-mismatch dynamics occurring at discontinuity zones (e.g., areas between the euphotic and mesopelagic zones) are known to affect trophodynamic structure and function within systems, such as the Humboldt Current (Escribano et al., 2004), the California Current (Alldredge et al., 1984; Roemmich and McGowan, 1995), and Black Sea (Vinogradov et al., 1985) ecosystems. For zooplankton population dynamics, spatial variability occurring with depth is likely more important than variability in the horizontal plane (e.g. Dagg, 1977; Longhurst and Harrison, 1989). Levels of abiotic factors such as temperature and salinity may exceed tolerance limits within clines thereby creating physiological barriers which not only hinder accessibility of phytoplankton for herbivorous zooplankton but may also protect zooplankton from their predators. Thus, small scale physico-chemical structures within highly stratified systems can impact the spatial overlap thereby influencing key bottom-up and top-down trophodynamic processes.

The Baltic Sea is the largest semi-enclosed, brackish water area of the world (Fonselius, 1970) where submarine sills separate a cascade of several deep basins (Matthäus, 1995). The hydrographic conditions are characterised by a summer thermocline and a permanent halocline (Fonselius, 1970) which restrict the water exchange between bottom and surface layers (Launiainen et al., 1987). Time series analyses have shown that zooplankton composition is affected by the strength of rainfall and river runoff (Viitasalo et al., 1995) and strongly influenced by episodic inflow events from the North Sea (e.g. Ojaveer et al., 1998; Möllmann et al., 2000; Möllmann and Köster, 2002) renewing and ventilating deep waters of higher salinity. These events are related to atmospheric circulation patterns and often followed by long stagnation periods (Matthäus and Frank, 1992; Matthäus and Schinke, 1994; Matthäus, 1995; Lehmann et al., 2002). The frequency of inflow events has decreased in the last decades which has been correlated to changes in zooplankton and fish populations within deep basins (Alheit et al., 2005).

Within Baltic Sea basins, decomposition processes often deplete oxygen and cause an anoxic zone at the seafloor (Fonselius, 1970; Laine et al., 1997). Both the horizontal and vertical distribution of marine, brackish, and limnic species of zooplankton are determined by physical gradients (Ackefors, 1969; Hernroth and Ackefors, 1979; Hansen et al., 2004; Schulz and Hirche, 2007) and small hydrographical changes can markedly alter the structure of the pelagic community. As several zooplankton species live at the edge of their physiological tolerance level in the Baltic Sea (Hernroth and Ackefors, 1979), recent hydrographic changes have had speciesspecific consequences and have caused alterations in the pelagic ecosystem (Viitasalo et al., 1995, 1998; Vuorinen et al., 1998; Ojaveer et al., 1998; Dippner et al., 2000; Möllmann et al., 2000; Dippner et al., 2008). Therefore the Baltic Sea is an ideal location for a detailed study of the role that hydrography plays in structuring the zooplankton community.

Despite the economically important fisheries for herring (Clupea harengus), sprat (Sprattus sprattus), and cod (Gadus morhua), knowledge on seasonal variability in the interactions among hydrography, zooplankton, and fish is still fragmentary. Although previous investigations have provided general overviews of the zooplankton distribution in relation to the stratified water column within Baltic Sea basins (e.g. Ackefors, 1969; Hernroth and Ackefors, 1979; Hansen et al., 2004), most previous studies suffered from sampling designs that lacked high enough spatial, temporal, and/or vertical resolution to detect only the largest and most general community patterns. In the present study, we describe a high resolution zooplankton data set from the Bornholm Basin (central Baltic Sea) obtained during the German Global Ocean Ecosystem Dynamics project (GLOBEC-Germany). Our anal- ysis provides detailed information on how seasonal and depthspecific hydrographic changes in the Bornholm Basin impact the zooplankton abundance, distribution, and species composition. We accomplished this by performing a multivariate data analysis of species' vertical abundance and relate changes in the seasonal abundance to prevailing environmental conditions. Previously published, broad-scale patterns of zooplankton in the Baltic Sea are reviewed by taxon and compared and contrasted to patterns observed during the GLOBEC-Germany field campaign in 2002 and 2003. Although some previous investigations have reported species-specific results, our community-wide analysis provides new insights into the structure of this ecosystem. Furthermore, we discuss potentially available prey fields in different depths and the impact of hydrography on trophodynamic relationships between zooplankton species and their predators, complimenting the analyses conducted within 3 GLOBEC-Germany companion papers appearing in this volume (Hinrichsen et al., this volume; Peck et al., this volume, Voss et al., this volume).

\section{Material and methods}

\subsection{Sampling}

Zooplankton samples were taken on 15 cruises between March 2002 and May 2003 (Table 1) with an almost monthly coverage. Sampling during the GLOBEC-Germany program was performed in stacked, $10 \mathrm{~m}$ intervals from a few metres above the seafloor to the surface with a multinet (Hydro-Bios, Kiel, $50 \mu \mathrm{m}$ mesh size, $0.25 \mathrm{~m}^{2}$ mouth opening, $0.2 \mathrm{~m} \mathrm{~s}^{-1}$ heaving speed) on nine focus stations in the Bornholm Basin (Fig. 1, Table 2). Positions and names of stations are congruent with former large projects in the Baltic (CORE, STORE, with 20-30 nautical miles between stations). Samples were collected regardless of the time of day and preserved in a buffered $4 \%$ formalin-seawater solution. At least 500 individuals of a sub-sample were enumerated and the number of individuals in the sub-sample extrapolated to individuals per cubic metre $\left(n \mathrm{~m}^{-3}\right)$ in each depth stratum. A total of 832 samples from different $10 \mathrm{~m}$ depth intervals was analysed. The spatial distribution of scyphomedusae was sampled by oblique Bongo net hauls (335 $\mu \mathrm{m}$ and $500 \mu \mathrm{m}$ mesh size, $0.6 \mathrm{~m}$ diameter) and the vertical distribution was studied by using a trawled BIOMOC ( $1 \mathrm{~m}^{2}$ opening, $55 \mu \mathrm{m}$-mesh size) or a trawled multinet $\left(0.25 \mathrm{~m}^{2}\right.$ opening, 335- $\mu$ m-mesh size) (for details see Barz and Hirche, 2005). As scyphomedusae were sampled by a different sampling procedure, they were not included in the statistical analyses. Vertical profiles of salinity, temperature and oxygen were determined by additional CTD casts.

All station, CTD and zooplankton data collected during the German GLOBEC project were given digital object identifiers and

Table 1

Schedule of the sampling campaigns.

\begin{tabular}{lll}
\hline Cruise & Cruise start (dd.mm.yyyy) & Cruise end (dd.mm.yyyy) \\
\hline AvH 44/02/08 & 12.03 .2002 & 22.03 .2002 \\
AL 200 & 02.04 .2002 & 30.04 .2002 \\
HE 168 & 05.05 .2002 & 24.05 .2002 \\
AvH 44/02/03 & 15.05 .2002 & 30.05 .2002 \\
AL 205 & 11.06 .2002 & 23.06 .2002 \\
AL 207/208 & 22.07 .2002 & 07.08 .2002 \\
HE 174 & 12.08 .2002 & 21.08 .2002 \\
AL 210 & 03.09 .2002 & 13.09 .2002 \\
AvH 44/02/11 & 30.09 .2002 & 10.10 .2002 \\
HE 181 & 11.11 .2002 & 29.11 .2002 \\
HE 182 & 13.01 .2003 & 24.01 .2003 \\
AvH 44/03/01 & 10.02 .2003 & 21.02 .2003 \\
AL 217 & 03.03 .2003 & 22.03 .2003 \\
AL 219 & 17.04 .2003 & 28.04 .2003 \\
AL 220_02 & 15.05 .2003 & 03.06 .2003 \\
\hline
\end{tabular}




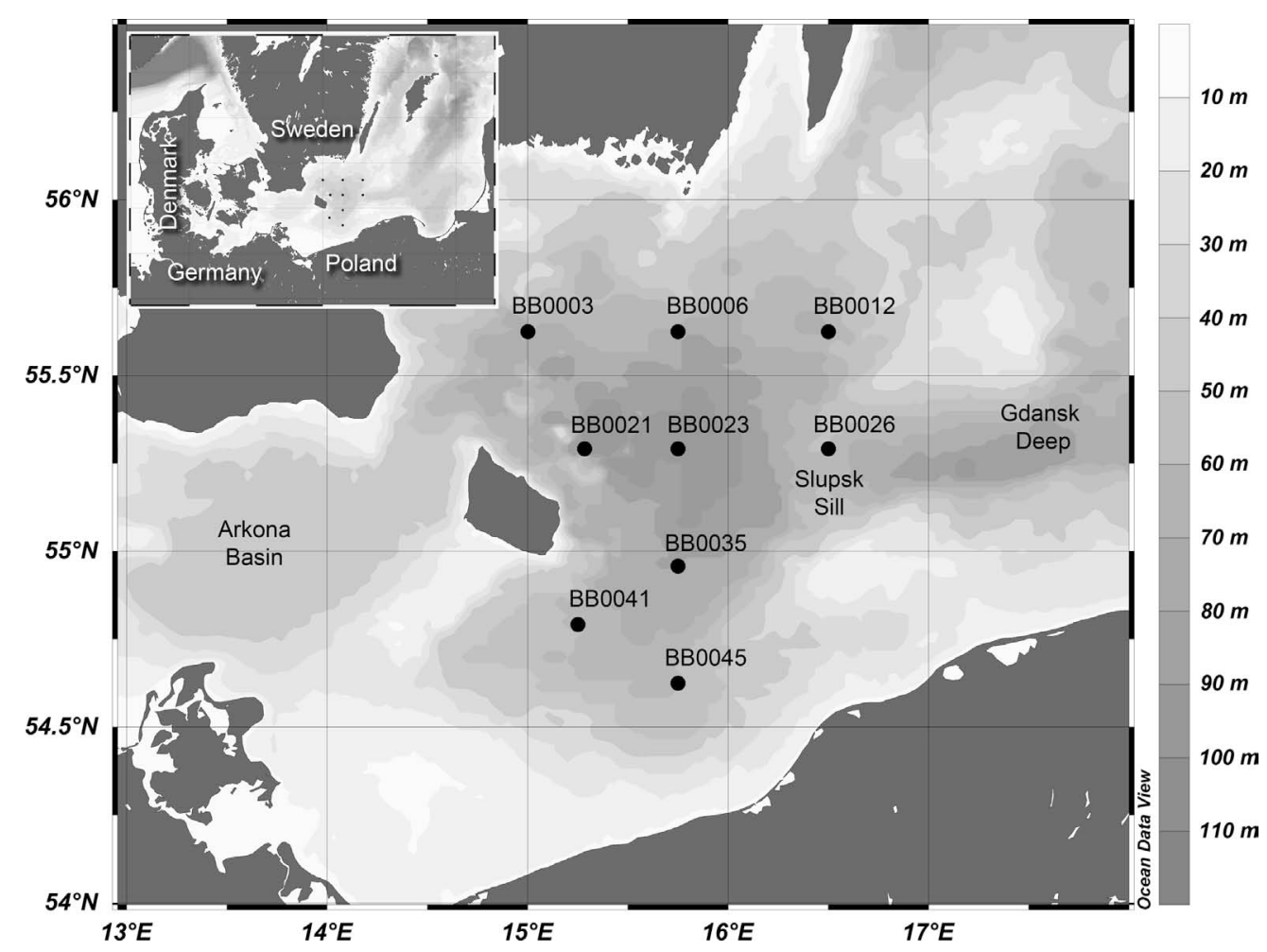

Fig. 1. The positions of the nine focus-stations in the Bornholm Basin.

Table 2

The positions of the nine focus stations in the Bornholm Basin.

\begin{tabular}{llll}
\hline $\begin{array}{l}\text { Station } \\
\text { name }\end{array}$ & $\begin{array}{l}\text { Latitude }\left({ }^{\circ} \mathrm{N}\right) \\
(\text { dec. })\end{array}$ & $\begin{array}{l}\text { Longitude }\left({ }^{\circ} \mathrm{E}\right) \\
(\mathrm{dec} .)\end{array}$ & $\begin{array}{l}\text { Bottom depth } \\
(\mathrm{m})\end{array}$ \\
\hline BB0003 & 55.625 & 15.000 & 75 \\
BB0006 & 55.625 & 15.750 & 70 \\
BB0012 & 55.625 & 16.500 & 65 \\
BB0021 & 55.292 & 15.283 & 85 \\
BB0023 & 55.292 & 15.750 & 95 \\
BB0026 & 55.292 & 16.500 & 65 \\
BB0035 & 54.958 & 15.750 & 85 \\
BB0041 & 54.792 & 15.250 & 70 \\
BB0045 & 54.625 & 15.750 & 60 \\
\hline
\end{tabular}

can be found on the World Data Centre Pangaea: http://doi.pangaea.de/10.1594/PANGAEA.761656.

\subsection{Data preparation}

With respect to the zooplankton obtained from a single net in a specific haul, the abundance was calculated in both volume-based $\left(n \mathrm{~m}^{-3}\right)$ and area-based $\left(n \mathrm{~m}^{-2}\right)$ units. The latter unit was computed from the volume-based data and converted using Ocean Sneaker's Tool (Schulz, 2005). For the preparation of maps, Ocean Data View was used (Schlitzer, 2004).

To identify the relative importance of a taxon in the Bornholm Basin, mean abundances $\left(n \mathrm{~m}^{-2}\right)$ were calculated from the data of the nine stations and displayed seasonally as relative numbers to visualise abundance cycles. As abundance depended upon the hydrographic situation at a station (depth and absence of the volume below the halocline on shallow stations), these values were considered more a proxy for temporal appearance rather than an overall estimate of abundance. The proportion of summed $n \mathrm{~m}^{-2}$ abundances from each cruise was determined for every taxon (Fig. 3 and Table 3 ).
Table 3

Mean abundance $\left(n \mathrm{~m}^{-2}\right)$ of zooplankton taxa in the Bornholm Basin for all cruises.

\begin{tabular}{|c|c|c|c|}
\hline Taxon & $\begin{array}{l}\text { Individuals } \\
\left(\sum\left(\varnothing n \mathrm{~m}^{-2}\right)\right)\end{array}$ & $(\%)$ & Included in MDFA \\
\hline Appendicularia & $2,190,744$ & 8.28 & \\
\hline Fritillaria borealis & $2,186,267$ & 8.26 & Yes \\
\hline Oikopleura dioica & 4476 & 0.02 & Yes \\
\hline Bivalvia & $1,936,222$ & 7.32 & \\
\hline Larvae and subadults & $1,936,222$ & 7.32 & Yes \\
\hline Cladocera & $3,619,520$ & 13.67 & \\
\hline Bosmina coregoni maritima & $2,858,967$ & 10.80 & Yes \\
\hline Evadne nordmanni & 737,565 & 2.79 & Yes \\
\hline Podon juveniles & 2781 & 0.01 & No \\
\hline Podon intermedius & 7530 & 0.03 & Yes \\
\hline Podon leuckarti & 12,676 & 0.05 & Yes \\
\hline Copepoda & $12,330,371$ & 46.59 & \\
\hline Acartia spp. nauplii & $1,705,903$ & 6.45 & No \\
\hline Acartia bifilosa C1-C6 & 678,700 & 2.57 & Yes \\
\hline Acartia longiremis $\mathrm{C} 1-\mathrm{C} 6$ & $1,159,052$ & 4.38 & Yes \\
\hline Centropages hamatus & $1,024,915$ & 3.87 & Yes \\
\hline Eurytemora sp. & 64,563 & 0.24 & Yes \\
\hline Oithona similis & $1,225,831$ & 4.63 & Yes \\
\hline Pseudocalanus spp. & $2,702,873$ & 10.21 & Yes \\
\hline Temora longicornis & $3,768,530$ & 14.24 & Yes \\
\hline Ctenophora & 17,374 & 0.07 & \\
\hline Pleurobrachia pileus & 17,374 & 0.07 & No \\
\hline Polychaeta & 110,314 & 0.42 & \\
\hline Subadults & 93,945 & 0.36 & No \\
\hline Trochophora larvae & 16,368 & 0.06 & No \\
\hline Rotatoria & $6,258,531$ & 23.65 & \\
\hline Keratella sp. & 68,313 & 0.26 & Yes \\
\hline Synchaeta sp. & $6,190,218$ & 23.39 & Yes \\
\hline
\end{tabular}

Depth-resolved, raw abundance data in $n \mathrm{~m}^{-3}$ were used for the investigation of the vertical zooplankton distribution. For analyses on individual copepod species, data were binned in three classes: nauplii, C1-C3 and C4-C6. Additionally, information about 

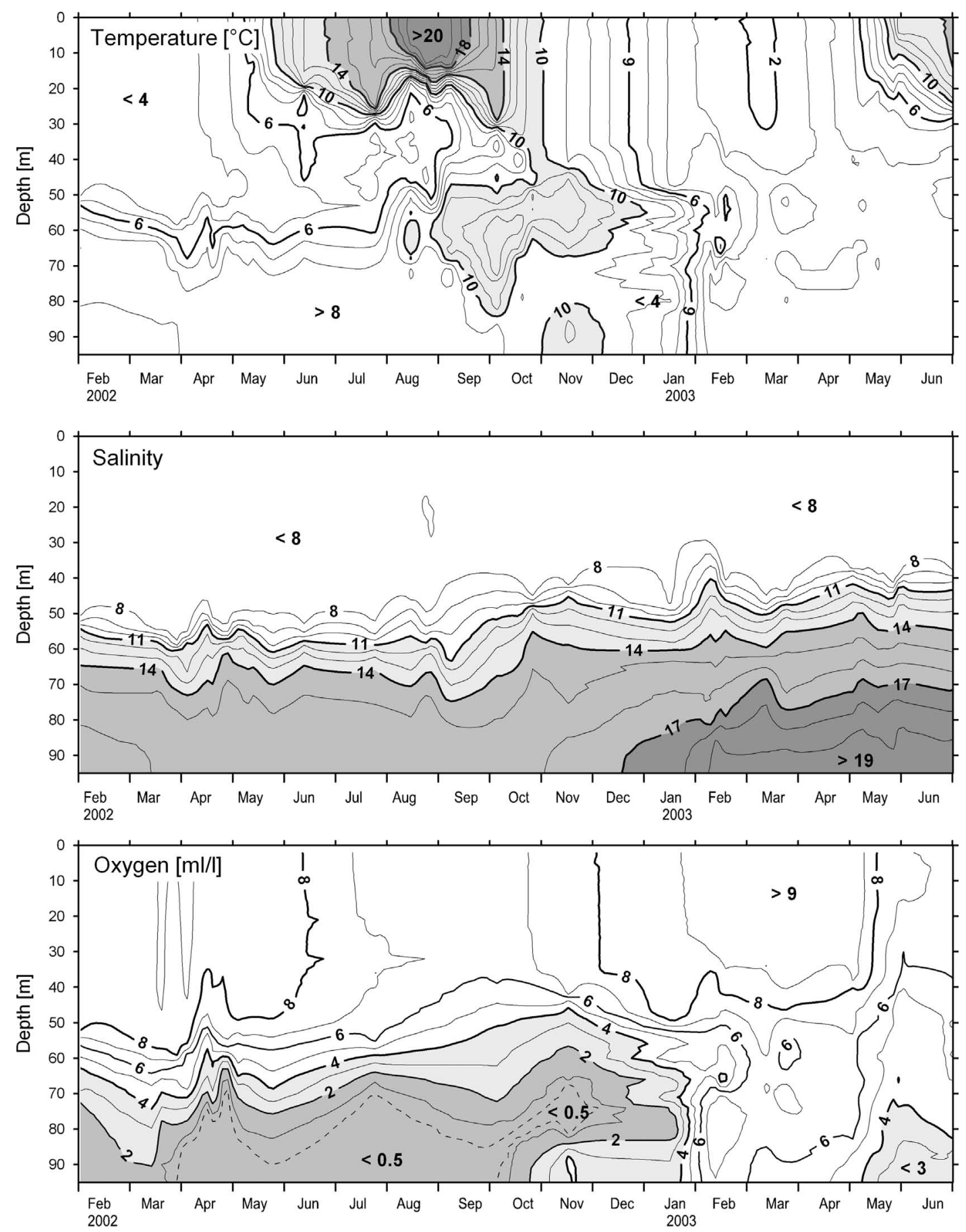

Fig. 2. Vertical profiles of temperature, salinity and oxygen in the central Bornholm Basin at position $55.3016^{\circ} \mathrm{N} / 15.7966^{\circ} \mathrm{E}$, station $\mathrm{BB} 0023$.

night- and day-haul was retrieved by comparing the start time of the sampling event and sunrise/sunset on that date calculated using the algorithms of Meeus (1994).

\subsection{Statistical analysis}

To identify vertical zooplankton distribution in relation to the ambient hydrography a one way ANOVA can be used for each taxon with group response as explanatory variables, resulting in an individual analysis for each taxon. The problem with this approach is that it ignores any multivariate relationships. Groups of species may have similar or different responses to clines or levels of abiotic factors and one of the hypotheses of GLOBEC-Germany was that the characteristic stratification in the Bornholm Basin shapes the zooplankton community and is critical to food web interactions. Thus, we utilised Multivariate Discriminant Function Analysis (MDFA; Fisher, 1936) to test whether the depth-specific species composition of zooplankton could be distinguished by the prevailing hydrographic conditions in the different depth strata. The MDFA is used to identify whether samples assigned to naturally occurring groups (nominal level), could be discriminated by compositional differences in species abundance. One advantage of the MDFA approach is that data do not need to be normally distributed for the initial model set-up (Hair et al., 1998). Each sample 

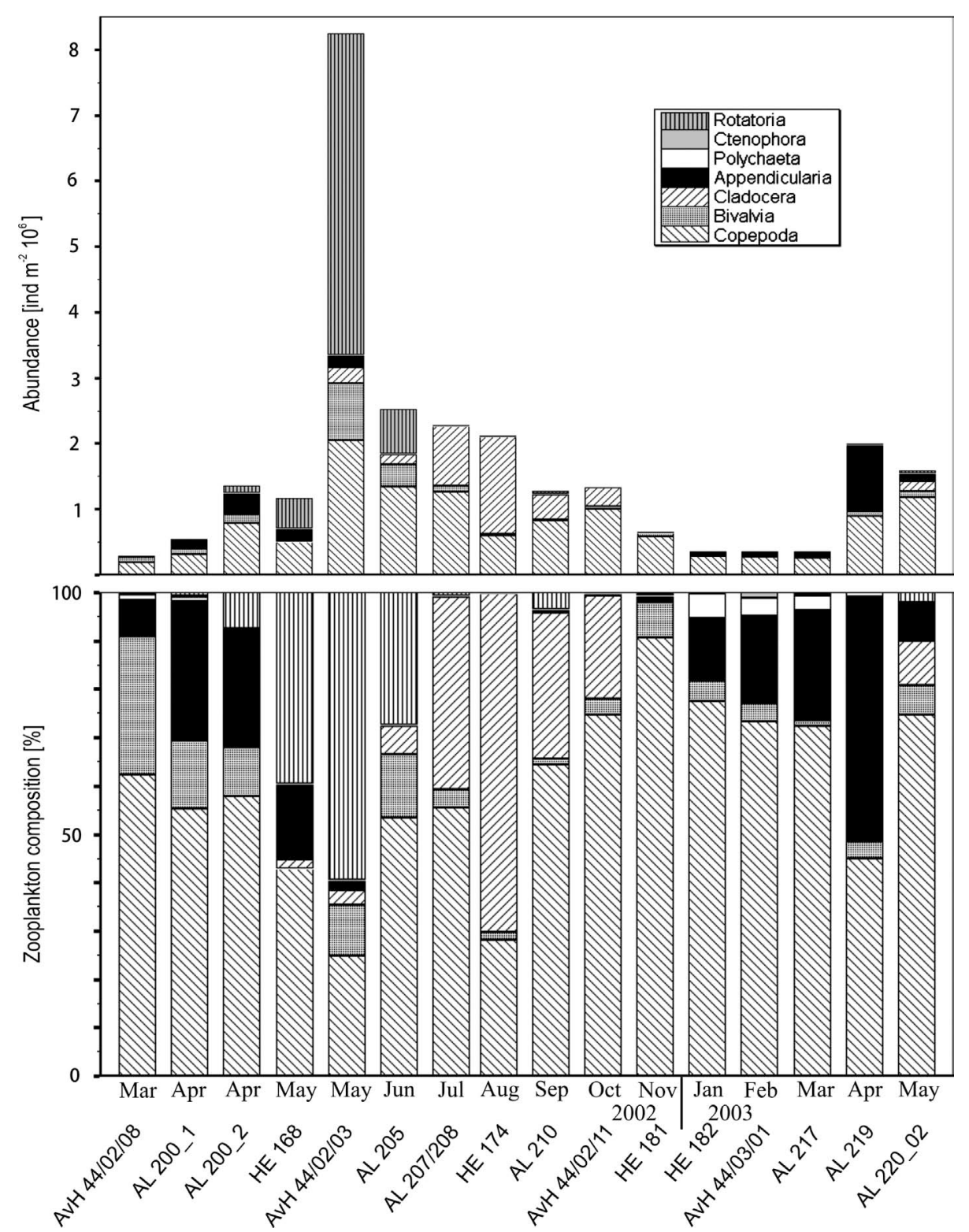

Fig. 3. Seasonal composition und structure of the zooplankton community in the Bornholm Basin. Data are pooled over the nine stations in the Bornholm Basin.

is assigned to one of the nominal groups using a probability calculated from the included factors. The classification is then compared with the a priori defined group membership.

To utilise MDFA on our GLOBEC-Germany zooplankton data, continuous, depth-resolved CTD data were averaged in $10 \mathrm{~m}$ layers corresponding to depths of zooplankton sampling. An averaged layer temperature (ALT) and salinity (ALS) was then assigned to each zooplankton sample. In one case (Cruise AL 200 leg 1, BB0041, April 2002) values for the uppermost $10 \mathrm{~m}$ interval had to be extrapolated, as measurements were missing. As temperatures were generally low in April 2002, no salinity gradient was expected in the uppermost layer and comparison with other stations showed no remarkably development of a thermocline, values from the depth stratum 10-20 m were used to replace missing data.

Based on the ALS and ALT values water masses of each $10 \mathrm{~m}$ interval were characterised. Threshold values were chosen based upon those that best represented the water masses during the vast majority of the seasonal cycle in the different zooplankton depth sampling layers.
Relatively saline bottom and inflow waters had ALS values $>9$. Extremely high ALS values $(\geqslant 16)$ indicated that the water mass belonged to one of the deep North Sea inflow events between November 2002 and March 2003. In the Bornholm Basin, these inflow waters extended down to the seafloor (>90 $\mathrm{m}$ depth) and were referred to as $B B 90$. Waters with intermediate salinity $(9<$ ALS $<16)$ were further discriminated by temperature. An ALT $>9{ }^{\circ} \mathrm{C}$ indicated waters of the summer inflow that shoaled at approximately $60 \mathrm{~m}$ depth that were termed $B B 60$. The normal (non-inflow) water mass that occurred below the halocline is colder $\left(\right.$ ALT $\left.\leqslant 9{ }^{\circ} \mathrm{C}\right)$ and was denoted as HALINE. Our use of the name $B B 90$ for a category in the MFDA differs from the definition used by Baltic Sea oceanographers (cf. Feistel et al., 2003a). Since we were interested in how distinguishable water masses (and ecological conditions in those water masses) might be related to differences in the zooplankton community, we included all deep, highly saline, and cold inflows in this group (respectively water masses within a $10 \mathrm{~m}$ interval having an ALS $\geqslant 16$ ).

An ALS $\leqslant 9$ was interpreted to be a water mass above the halocline that was further distinguished by temperature as either the 


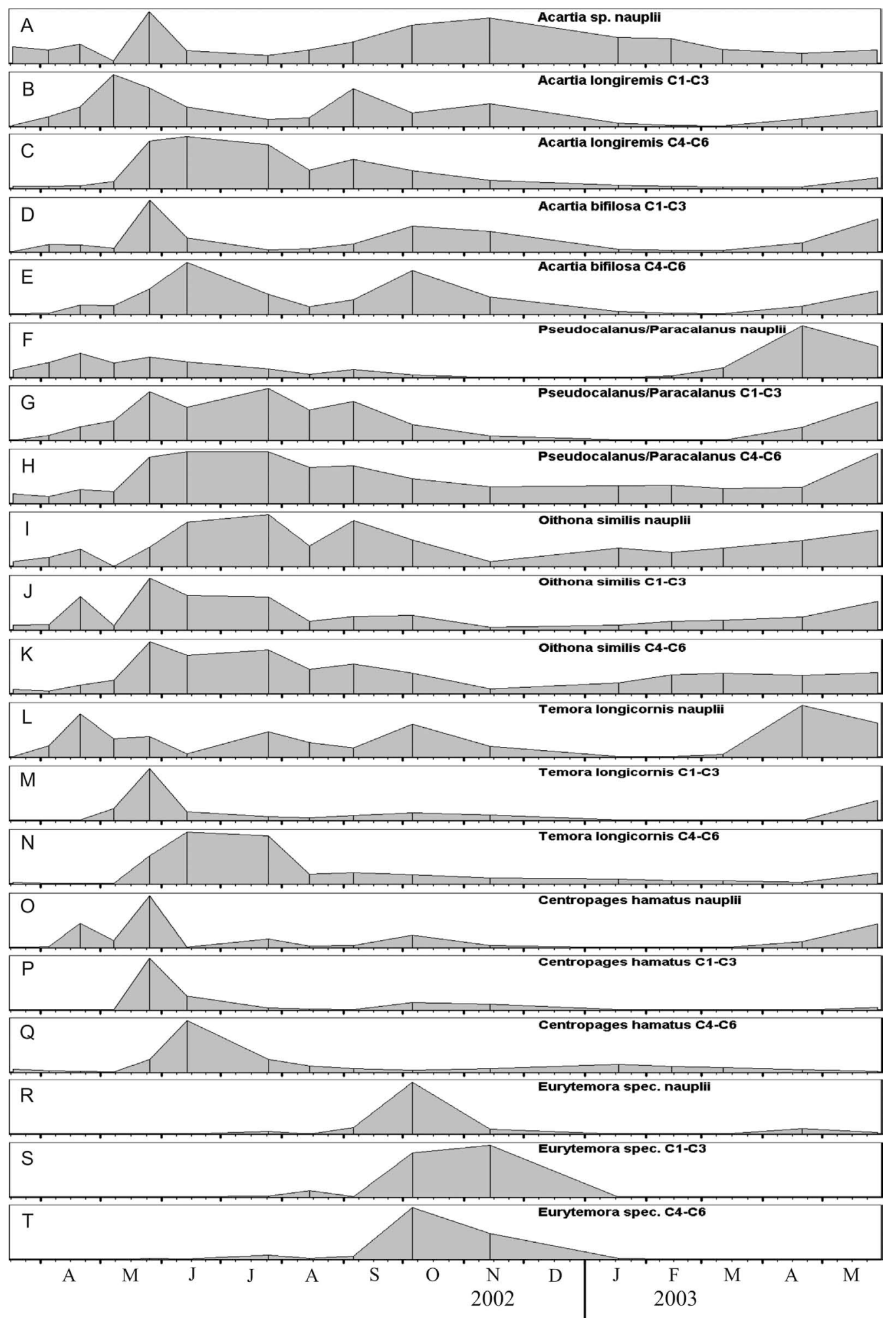

Fig. 4. Seasonal patterns in the abundance of copepods. The scaling of abundance is normalised to one and vertical lines indicate sampling dates.

warm surface layer during summer (ALT $>8^{\circ} \mathrm{C}$, termed SUMMER) or colder ALT during winter $\left(\leqslant 8^{\circ} \mathrm{C}\right.$, termed WINTER).

For the analysis, data on the abundance of the 23 dominant plankton species and taxa were used as variables (Table 3). Nauplii, polychaeta, Pleurobrachia pileus, and Scyphomedusae were excluded from the analysis. It was expected that the behaviour of those four groups would not be as distinct as that of the other planktonic species. Prior to analyses, zooplankton data $\left(n \mathrm{~m}^{-3}\right)$ were $\log (1+x)$ transformed. Each of the 832 samples was assigned to one of the categories SUMMER, WINTER, HALINE, BB60 or BB90. A more detailed explanation of the method utilised here is provided by Schulz et al. (2007). 


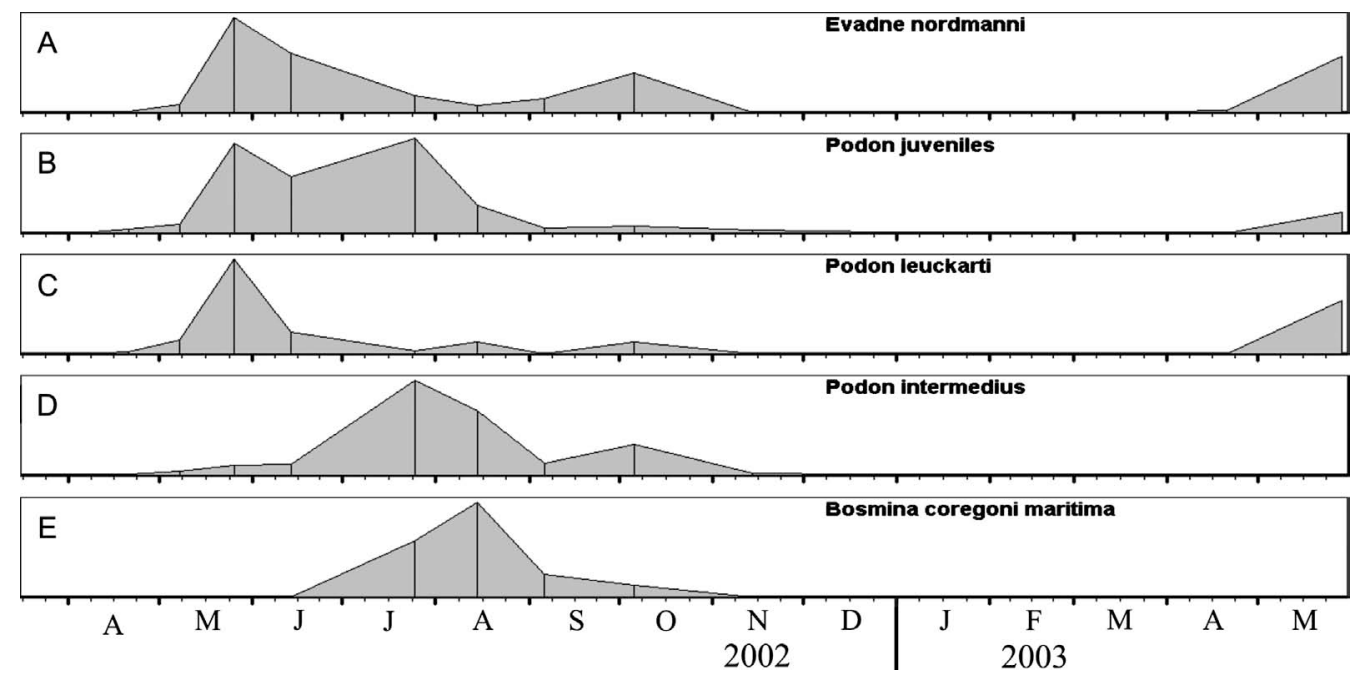

Fig. 5. Seasonal patterns in the abundance of cladocerans. The scaling of abundance is normalised to one and vertical lines indicate sampling dates.

\section{Results}

\subsection{Hydrography}

During the 2002 and 2003 GLOBEC-Germany sampling period, a typical hydrographic situation in the central Baltic Sea was encountered, being characterised by strong vertical gradients. The halocline was located at 50-60 m depth in April 2002 but was shallower (40-50 m) in November 2002 (Fig. 2). During this 8 -month period, salinity was $<8$ above the halocline and $>14$ below the halocline. In March 2002, the sea surface temperature (SST) in the upper mixed layer was $\sim 2{ }^{\circ} \mathrm{C}$ and increased from $4{ }^{\circ} \mathrm{C}$ in the middle of April to $10^{\circ} \mathrm{C}$ at the end of May 2002. In May 2002, a relatively strong thermocline developed at $20 \mathrm{~m}$ depth. In the upper $30 \mathrm{~m}$, waters were $\sim 13{ }^{\circ} \mathrm{C}$ in June but warmed to $>17^{\circ} \mathrm{C}$ in July and were $>20^{\circ} \mathrm{C}$ in the upper $20 \mathrm{~m}$ in August. These warm, late summer temperatures likely resulted from relatively calm weather conditions during that period (Mohrholz et al., 2006). Temperatures started to decline after August and the thermocline was absent by November 2002 .

In late summer, a series of inflow events terminated a long stagnation period in the Baltic Sea. Feistel et al. (2003a, 2003b, 2004), Mohrholz and Schuffenhauer (2004) and Mohrholz et al. (2006) provide detailed descriptions of hydrographical changes caused by these inflow events. In short, an inflow event occurred between August and October 2002 and was characterised by reduced water density with waters at $60 \mathrm{~m}$ depth $(B B 60)$ by having the highest annual temperature (up to $13.8^{\circ} \mathrm{C}$ ) on record (Feistel et al., 2004). The water of a second inflow was more saline and displaced bottom waters which gradually flowed out of the Bornholm Basin across the Słupsk Sill and into the Gdansk Deep by December (Fig. 1). The oxygen concentration of bottom waters increased to $>2 \mathrm{ml} \mathrm{l}^{-1}$ (Fig. 2).

In January 2003, the first Major Baltic Inflow (MBI) of cold, saline North Sea water took place after a 7 year absence (Feistel et al., $2004)$ causing a steep increase in the bottom water salinity $(>18)$ and completely replaced the deep waters of the previous, smaller inflow events. After that time, the water cooled down to $\sim 2.5^{\circ} \mathrm{C}$ above the halocline and $4{ }^{\circ} \mathrm{C}$ below the halocline and remained relatively cold until May. Consequently, during the spring of 2003, waters were $1.5{ }^{\circ} \mathrm{C}$ colder in the mixed layer and $4{ }^{\circ} \mathrm{C}$ colder in the rest of the water column than during the spring of 2002 (Fig. 2). These inflow events markedly changed the oxygen profile of the study region. Dissolved $\mathrm{O}_{2}$ concentrations were $>6 \mathrm{ml} \mathrm{l}^{-1}$ at all times above the halocline but were $<1 \mathrm{ml} \mathrm{l}^{-1}$ in deep waters prior to inflows (between April and October 2002). The MBI ventilated the deeper part of the Bornholm Basin and $\mathrm{O}_{2}$ concentrations increased to $6 \mathrm{ml} \mathrm{l}^{-1}$ between the halocline and the bottom and remained $>4 \mathrm{ml} \mathrm{l}^{-1}$ until May 2003 and $>2 \mathrm{ml} \mathrm{l}^{-1}$ until August 2003 (Mohrholz et al., 2006).

\subsection{Zooplankton composition}

In the samples collected with fine $(50 \mu \mathrm{m})$ mesh multinets, the zooplankton community composition could be classified into six groups: Rotatoria, Ctenophora, Polychaeta, Appendicularia, Cladocera, Bivalvia, and Copepoda (Fig. 3). Copepods were by far the most abundant group (Fig. 3, Table 3), followed by rotifers, cladocerans, appendicularians, and Bivalvia. Each of these major groups was characterised by one or only a few species. The five most abundant species were Synchaeta spp. (23.4\%), Temora longicornis (14.2\%), Acartia spp. (13.4\%), Bosmina coregoni maritima (10.8\%), and Pseudocalanus sp. (10.2\%). Of minor importance were Fritillaria borealis, Bivalvia larvae, Oithona similis, Centropages hamatus and Evadne nordmanni (listed in descending order of abundance). Oikopleura dioica, Podon spp., Eurytemora sp., Pleurobrachia pileus, polychaetes and Keratella spp. contributed $<1 \%$ of zooplankton composition abundance. As previously mentioned, scyphomedusae (also Pleurobrachia spp.) were not analysed due to their often patchy distribution and the fact that net sampling generally underestimates the abundance of gelatinous zooplankton (cf. Graham et al., 2001).

\subsection{Seasonal cycles}

While copepods mainly dominated the zooplankton throughout the year, other taxa had relatively large, but brief peaks in abundance (Fig. 3, upper panel). The total number of organisms displayed a modal distribution with low abundances in winter, a rapid increase in April (Fig. 3, upper panel), and a pronounced maximum at the end of May 2002, which was 20-fold higher than that observed during the winter. The zooplankton composition during the period of maximum abundance (Fig. 3, lower panel) consisted, to a large degree, of rotifers (59.4\%), which may have hatched from resting eggs at that time, and copepods (24.7\%). Cladocerans were most prominent between July and October with a maximum of $69.9 \%$ in August, mainly due to the abundance of Bosmina coregoni maritima. This species dominated the summer zooplankton community and started to increase in abundance in parallel with warming temperatures in the surface layer. An even more pro- 

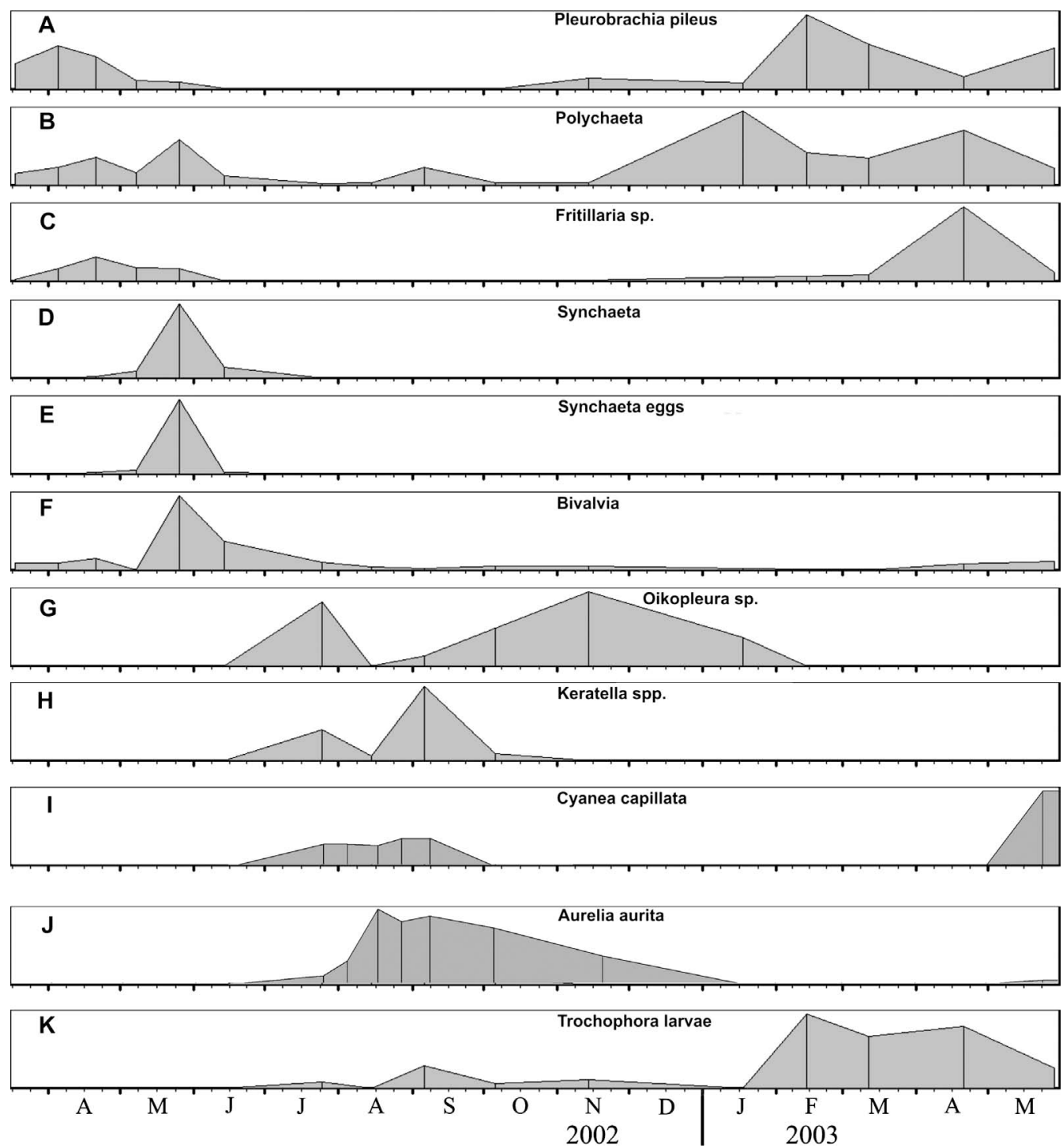

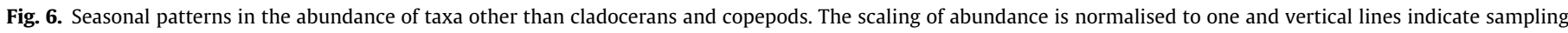
dates.

nounced and short-lived peak in abundance was observed for rotifers in May 2002 (formed by Synchaeta spp.). The rest of the time the community was dominated by copepods particularly during winter 2002/2003 when copepods comprised $>90 \%$ of the zooplankton abundance. Other taxa had pronounced peaks in winter/spring and were more or less absent for long periods during the year. Appendicularians comprised almost $30 \%$ of the zooplankton sampled in early April 2002 and 50\% in April 2003. Bivalve larvae (meroplankton) comprised $28.5 \%$ of the zooplankton abundance during their peak occurrence in March 2002.

\subsubsection{Seasonal patterns by taxon}

In the following, we briefly describe the dominant seasonal patterns in occurrence of members of the Copepoda (Fig. 4), Cladocera (Fig. 5) and other taxa (Fig. 6). In each case, the seasonal abundance is normalised to the maximum observed during the 14.5 month survey campaign in the Bornholm Basin (all nine stations were summed) and panels are organised (top to bottom) according to the first appearance of peak values in samples. Copepods were resolved to the species and stage levels.

3.3.1.1. Copepods. Acartia spp. nauplii were not identified to the species level but they most likely belonged to A. bifilosa and A. lon- giremis. Acartia spp. nauplii were already abundant in March 2002 and declined until the beginning of May 2002 (Fig. 4A). However, at the end of May, Acartia naupliar abundance reached peak values. Thereafter, the abundance of nauplii decreased until August and reached a second maximum in the middle of November 2002. Of the two dominant species in the Bornholm Basin, Acartia longiremis early copepodites ( $\mathrm{C} 1-3$ ) first appeared at the end of April, peaked in May 2002 and displayed a second (lower) and third (marginal) peak in early September and November 2002, respectively (Fig. 4B). The later stages (C4-C6) were abundant from May through August 2002 (Fig. 4C). Early copepodites of the second member of the Acartia genus, Acartia bifilosa, displayed three peaks in abundance: end of May 2002, during October 2002, and in May 2003 (Fig. 4D). The first peak for the C1-3 was found at the end of May 2002, the second in October 2002. After low abundances in winter the onset of the new generation was observed in April 2003. Peaks in later-stage copepodites (C4-C6) of A. bifilosa occurred about 2 weeks after those of the younger stages (Fig. 4D).

It is difficult to separate Pseudocalanus spp. and Paracalanus parvus. Thus, they have been combined here (although it should be noted that the GLOBEC work by Renz and Hirche (2006) indicated that these samples were likely dominated by Pseudocalanus acuspes). In 2002, nauplii and copepodites of the Pseudo-Paracal- 
anus spp. group were most abundant between April and June, and May and October, respectively, although individuals were found in all months of that year (Fig. $4 \mathrm{~F}$ and $\mathrm{G}$ ). However, the clear peak in abundance of nauplii of Pseudo-Paracalanus spp. occurred after the MBI at the beginning of 2003 (Fig. 4F) and the abundance of older stages increased towards the end of May 2003 (Fig. 4G and H). Similar to the Pseudo-Paracalanus group, Oithona similis was found throughout the year and its nauplii and copepodite stages reached their highest abundances between May and September 2002 (Fig. 4I-K).

Sampling in 2002 captured the life cycle development of Temora longicornis as naupliar, $\mathrm{C} 1-\mathrm{C} 3$, and C4-C6 stages primarily occured in April, at the end of May, and in June, respectively (Fig. 4L-N). The abundance of late-stage copepodites remained high until the end of July 2002 (Fig. 4N) and a second peak in the abundance of nauplii was observed in October 2002 but few nauplii were found during the winter (Fig. 4L). The peak abundance of Temora nauplii in April 2003 was higher than that in 2002. In May 2003, an increase in early copepodite abundance was observed but field sampling was completed prior to the occurrence of any peak in later-staged copepodites.

Unlike Acartia, Pseudocalanus, and Temora, two copepods (Centropages hamatus and Eurytemora spp.) only exhibited relatively brief periods of abundance. First, Centropages was only important between April and June. Nauplii of this species were found at the end of April and reached maximum abundance in late May when C1-C3 stages were also abundant (Fig. 40-Q). Second, species in the Eurytemora genus exhibited one peak between September and November 2002. Naupliar, C1-C3, and C4-C6 stages were all found in high abundance in early October 2002 after a strong increase during the previous 4 weeks. The presence of the $\mathrm{C} 1-\mathrm{C} 3$ stages lasted several weeks and the maximum was found in November 2002 (Fig. 4R-T).

3.3.1.2. Cladocerans. Cladocerans within three genera (Evadne, Podon and Bosmina) formed an important component of the summer zooplankton community in the Bornholm Basin and four species were identified (E. nordmanni, P. intermedius, P. leuckarti, and $B$. coregoni martitima) (Fig. 5). Evadne was present in samples collected in March 2002 and increased by four orders of magnitude until the end of May 2002 (Fig. 5A). A steady decline of the population was observed from the end of May to August but a second increase was observed in September (after the BB60 inflow) that lasted through October 2002. Similar to the other cladocerans, Evadne rapidly declined in abundance to low levels throughout the autumn and winter until the onset of the next generation was observed in March/April 2003 (Fig. 5A). Juveniles of the two Podon congeners ( $P$. leuckarti and $P$. intermedius) had two consecutive peaks in abundance (end of May and July 2002) and a slight increase at the beginning of October 2002 but were not recorded again within samples until May 2003 (Fig. 5B). Adults of $P$. leuckarti and $P$. intermedius first appeared in March and April 2002, respectively, but the main peaks occurred 2-3 months later followed by smaller peaks in August/September and/or October 2002 (Fig. 5C and $\mathrm{D}$ ). These species were more or less absent from the water column from December until either February ( $P$. leuckarti) or April (P. intermedius) 2003. The abundance of both species started to increase in May 2003 but was lower than in the previous year. Finally, the abundance of Bosmina coregoni maritima, which was relatively low throughout most of the year in both 2002 and 2003, increased seven orders of magnitude between March and August 2002 (Fig. 5E), when it became one of the most numerically dominant species in the upper water layers.

3.3.1.3. Other taxa. Other routinely encountered members of the zooplankton community within samples included gelatinous zoo- plankton (ctenophores, appendicularians, and scyphozoans) as well as the larval stages of benthic organisms such as polychaetes and bivalves (Fig. 6). For gelatinous zooplankton, the ctenophore Pleurobrachia pileus was mainly observed between March and April in 2002, and its abundance was highest in April and declined until the end of July. No individuals were recorded until October but their abundance was low until mid February 2003 when increased to values that were 1.7-fold greater than those of the previous year (April 2002). Two months later, the abundance of Pleurobrachia had decreased and was lower in April 2003 compared to April 2002. In 2002, the medusae of both of the scyphozoans Cyanea capillata and Aurelia aurita were first observed at the end of July but the former only occurred until September whereas the latter were observed through November (Fig. 6I and J). In both cases, abundance in 2002 was highest in late summer but the peak abundance of Cyanea was observed in May 2003, near the end of our sampling campaign (Fig. 6I).

Appendicularians within two genera, Fritillaria and Oikopleura, were found in our GLOBEC-Germany samples and the former was, by far, more numerically dominant than the latter. Fritillaria borealis was present, at least in small numbers, throughout the year but became more abundant in both 2002 and 2003 at the end of March, peaked in the second half of April, and declined thereafter until the end of May (Fig. 6C). Peak abundance in April 2002 and 2003, was $320,000 \mathrm{n} \mathrm{m}^{-3}$ and $1.0 \times 10^{6} n \mathrm{~m}^{-2}$, respectively. During the summer, this species was absent at shallower stations (data not shown). The second appendicularian, Oikopleura dioica, occurred in summer with peaks at the end of July and in the middle of November (Fig. 6G), when the abundance of $F$. borealis was low. The latter peak coincided with the BB90 inflow that renewed the deep waters of the basin. A reverse situation was found after the MBI, when stock size decreased despite improved oxygen and salinity conditions below the halocline (see Fig. 2). In September 2002, $F$. borealis was associated with the warm $B B 60$ inflow waters at the entrance of the Bornholm Basin.

As previously mentioned, rotifers formed an important component of the zooplankton community in the Bornholm Basin during specific time periods and members of two genera (Keratella and Synchaeta) were found in our samples. Keratella spp. were most abundant between June and October 2002 (Fig. 6H) at stations closest to Bornholm Island (BB0021 and BB0041, spatial data not shown). This rotifer had two prominent peaks in abundance, one in July and a second, more intense peak in early September (Fig. 6H). Synchaeta spp. was first sampled in April 2002 at the deepest stations (BB0003, BB0021 and BB0023) and displayed one distinct peak in egg and adult abundance from May to June 2002 (Fig. 6D and E). Bivalve larvae displayed a similar seasonal pattern as the rotifers with a single peak in May/June (Fig. 6F). Bivalve larvae were also captured in May 2003, but at much lower abundance compared to 2002. The early (trochophore) and laterstaged pelagic larvae of polychaetes were found throughout the year in 2002 with small peaks occurring between the end of July and November but the abundance of trochophore and polychaete larvae was clearly highest after the MBI in 2003 (Fig. 6B and K).

\subsubsection{Depth-specific distribution patterns}

3.3.2.1. Copepods. Of the seven groups of copepods found in our GLOBEC-Germany samples, clear differences in depth distributions could be discerned particularly during specific periods of the year (Fig. 7) that, in many cases, could be classified by the dominant water mass characteristics. For example, when Acartia bifilosa was abundant in October 2002, it almost exclusively occurred in waters within and above the thermo- and halocline (Fig. 7). Without a thermocline the other Acartia congener (A. longiremis) was also present in these surface waters. Compared to A. bifilosa, early copepodite stages of $A$. longiremis occurred at higher abun- 
dance for a longer period of time (throughout the formation of the thermocline). A. bifilosa was mainly found above the thermocline, while $A$. longiremis was most dominant below, when summer surface temperatures were highest.

Ontogenetic differences in water mass utilisation were apparent in a number of copepod species. For example, more advanced developmental stages of $A$. longiremis preferred cooler waters. In winter, all stages occurred in the mixed layer above the halocline. Within the Pseudo- and Paracalanus spp. group, C4-C6 stages were most abundant below the halocline in cool waters when a thermocline was present, but these stages also utilised shallower waters in November 2002 after the breakdown of stratification. In contrast, naupliar and $\mathrm{C} 1-\mathrm{C} 3$ stages were also abundant at shallower water depths. Oithona similis represents another example of ontogenetic differences in vertical habitat utilisation. This species was always most abundant at stations deeper than $60 \mathrm{~m}$ and absent in depth strata that had dissolved oxygen concentrations $<0.5 \mathrm{ml} \mathrm{l}^{-1}$. Later-staged copepodites (C4-C6) inhabited deeper layers than naupliar and $\mathrm{C} 1-\mathrm{C} 3$ stages and were often found close to the halocline (Fig. 7). Anyhow, all stages dwelled continuously below the halocline.

Both diel and ontogenetic trends in vertical habitat utilisation were apparent in Temora longicornis where nauplii and C4-C6 stages were mainly found below the thermocline during the day but the former were also found in the thermocline and adjacent layers during night, but still seemed to avoid the warmest and uppermost water layers during the warmest season. During winter the stock was dominantly above the halocline in the well mixed surface waters. In March 2003, C4-C6 individuals were relatively rare and were found, to a large extent, in the slightly warmer waters above the halocline (Fig. 7). In C. hamatus, a copepod that exhibited only a relatively short period of abundance in our time series, also exhibited clear depth preferences and ontogenetic differences in vertical abundance. During peak abundance the C4C6 stages of $C$. hamatus were mainly found in deeper waters up to the layer of the thermocline, showing an avoidance of the uppermost warm layers above the thermocline. The $\mathrm{C} 1-\mathrm{C} 3$ stages also occurred within and above the thermocline during that time (Fig. 7). With the breakdown of the thermocline, all stages of $C$. hamatus dwelled in the upper mixed waters above the halocline.

Inflow events modified the copepod community by changing both depth distributions as well as species composition. For example, during the $B B 60$ and $B B 90$ inflows, Oithona was not only found at depths greater than $60 \mathrm{~m}$ but was also found in shallower regions of the halocline. In March 2003, Oithona was, to a large extent, found in slightly warmer waters around the halocline. Secondly, the brief peak in Eurytemora spp. coincided with the BB60 inflow from the North Sea, although advection into the Bornholm Basin is unlikely. During the brief presence of Eurytemora spp. in the plankton, this species occurred above the thermocline in October 2002 and in the upper mixed waters in November (Fig. 7).

3.3.2.2. Cladocerans. Cladocerans displayed one of the most clear depth preferences in our dataset with all species being most abundant during the warmest periods of the year within the uppermost water masses (Fig. 8). In Bosmina coregoni maritima, the most rapid increase in abundance occurred when SST was $>16^{\circ} \mathrm{C}$. Some of the highest abundances of this species in the Baltic Sea ( $>297,000 \mathrm{n} \mathrm{m}^{-3}$ in the upper $10 \mathrm{~m}$ at station BB0006 and more than 267,000 $n \mathrm{~m}^{-3}$ at BB0023) were recorded at the warmest temperatures $\left(\sim 20^{\circ} \mathrm{C}\right)$ which occurred in August (see Figs. 2 and 8 ). When the species was at low abundance (between January and May), it mainly occurred in the mixed layer above the halocline (not shown). The few specimens of Evadne nordmanni found in April 2002 occurred down to and even in the upper part of the halocline, a region that had warmer waters than the mixed surface layer (see Fig. 2). With warming beyond $4.5^{\circ} \mathrm{C}$ (in March 2002), the species was found in surface waters, a change in distribution that coincided with its dramatic increase in abundance that year. In 2003, the onset of the next generation of Evadne nordmanni occurred in waters above the halocline. When waters in the upper $10 \mathrm{~m}$ warmed above $\sim 15^{\circ} \mathrm{C}$, most individuals were found in the layer of the thermocline (Fig. 8). Finally, the vast majority of adults of the two Podon congeners were found above the thermocline between May and June (Fig. 8). With the $B B 60$ inflow, the few $P$. intermedius individuals remaining were also found in the more saline and warmer inflow waters while P. leuckarti displayed a slight increase in abundance.

3.3.2.3. Other taxa. Gelatinous zooplankton also tended to exhibit depth partitioning. For example, the main proportion of the stock of Pleurobrachia pileus was found above the halocline with low abundances in layers with ALS > 11.5 (Fig. 9). Above the halocline, the highest abundance was mainly observed in layers with the coldest waters. As the thermocline developed, P. pileus entered (was captured in) deeper, cooler waters and this species decreased in abundance. Scyphozoans also displayed different depth preferences with Aurelia aurita mainly found in the upper $20 \mathrm{~m}$ throughout the summer and only caught in deeper depths (around $40 \mathrm{~m}$ ) in November. In contrast, the medusae of Cyanea capillata were much less abundant than those of $A$. aurita and only occurred within intermediate water layers and the halocline $(50-60 \mathrm{~m})$ (data not shown). In terms of the most common appendicularian (Fritillaria borealis), after the thermocline developed, the population was only found below the halocline, while it was also present above the halocline the rest of the year (Fig. 9). During the warm period specimens were rare at shallow stations.

The two rotifers found in our survey displayed contrasting depth distribution. Keratella individuals were mainly found above the thermocline in stratified waters (Fig. 9) (and along the shallower borders of the station grid, data not shown). In contrast, Synchaeta spp. were most abundant early in the year, when the thermocline started to develop. At that time they were mainly found in WINTER waters (Fig. 9), compared to the adjacent water layers. When the population started to decline, adults and eggs both occurred at high abundance also above the thermocline at some stations. Polychaete larvae also appeared to avoid water layers above the thermocline but were found throughout the water column during time periods lacking thermal stratification (Fig. 9). The younger (trochophore) larvae were mainly recorded in deeper layers with higher salinity. Finally, the larvae of bivalves were consistently found in the upper water layers. When SST was $>11^{\circ} \mathrm{C}$, larvae were more abundant closer to the thermocline than to the uppermost layers (Fig. 9).

\subsubsection{Plankton composition related to water masses}

To evaluate the association of zooplankton taxa with the different water mass categories a Multivariate Discriminant Function Analysis (MDFA) with a subsequent Canonical Analysis (CA) was performed. The results of the MDFA indicated that samples from different water types can be distinguished by their characteristic species composition (Fig. 10, upper panel). The classification accuracy of the model based upon species composition was $84 \%$ (Table 4). Wilk's $\lambda$ (normality cannot be fully achieved with these ecological data) as well as $p$-values from an $F$-test indicated significant discrimination and implied that the species composition varied characteristically among the hydrographic categories. Discrimination was best for the low saline SUMMER and WINTER waters (Table 4 ) and weakest among waters with higher salinity (HALINE, BB60, and BB90).

Subsequently, a Canonical Analysis (CA) was performed. The first two roots of the CA explained more than $95 \%$ of the observed 

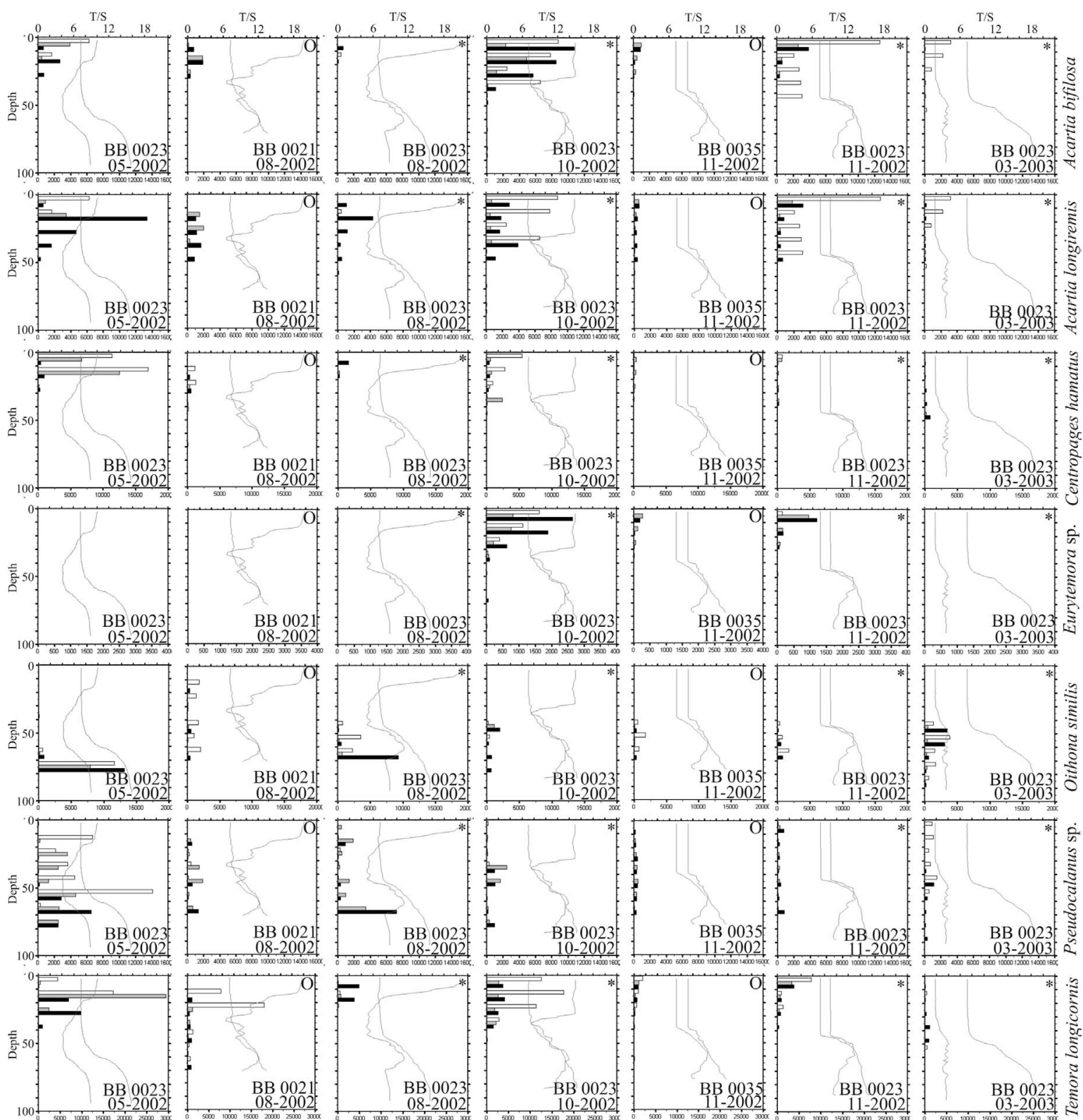

Fig. 7. Vertical distribution of taxa other than cladocerans and copepods. Note the different scaling. Day hauls are indicated by an open circle, night hauls by asterisk.

variance, although the first three roots were significant (step down $\chi^{2}$ test, Table 5). The canonical mean values of the hydrographic categories (Table 6 , arithmetic sign) indicated that the first root separated waters of the SUMMER category from the remaining. The value for the WINTER category was close to the separating hyperplane and appeared to have an intermediate state between the SUMMER category and the more haline waters. Thus, the first root appears to reflect the general vertical hydrographic stratification observed through the year. The hyperplane set up by the second root solely separated the samples of the WINTER category (Table 6). Although both roots showed a numerical distance of the $B B 60$ waters to the HALINE and $B B 90$ waters, total distance to the separating hyperplane was that high to deny a significant impact in discrimination among the haline waters. The third root was neglected, as it explained $<4 \%$ of the variance and Wilk's $\lambda$ was high (Table 6).

The Canonical Factor Structure Coefficients (CFSC) of the CA represent the loadings of the variables in the analysis and allow species distribution to be interpreted with respect to the hydrographic cat- egories (Fig. 10, lower panel). Based on the knowledge of the roots, the different quadrants reflect compositional differences that were characteristic for the different hydrographic categories. The intermediate state of the WINTER category on the first root most probably arises from at least partial compositional similarities with the waters above (SUMMER) and below (the more haline waters). CFSC values above zero on the first root can be interpreted to represent variables (taxa), that were most abundant above the halocline in waters of the categories SUMMER and WINTER. In turn, CFSC values below zero represent variables having the highest loadings in the analysis for the WINTER category and higher saline waters. The same holds for the interpretation of second root where values below zero represent taxa associated with the WINTER category waters.

Thus, displaying CFSC values in a 2d-plot (Fig. 10, lower panel) allows the interpretation of dominant taxa inhabitation by the quadrants (enumeration follows mathematical order) set up from the MDFA hyperplanes:

Quadrant I includes all species that utilise the SUMMER category above the thermocline. Species being present here have to 

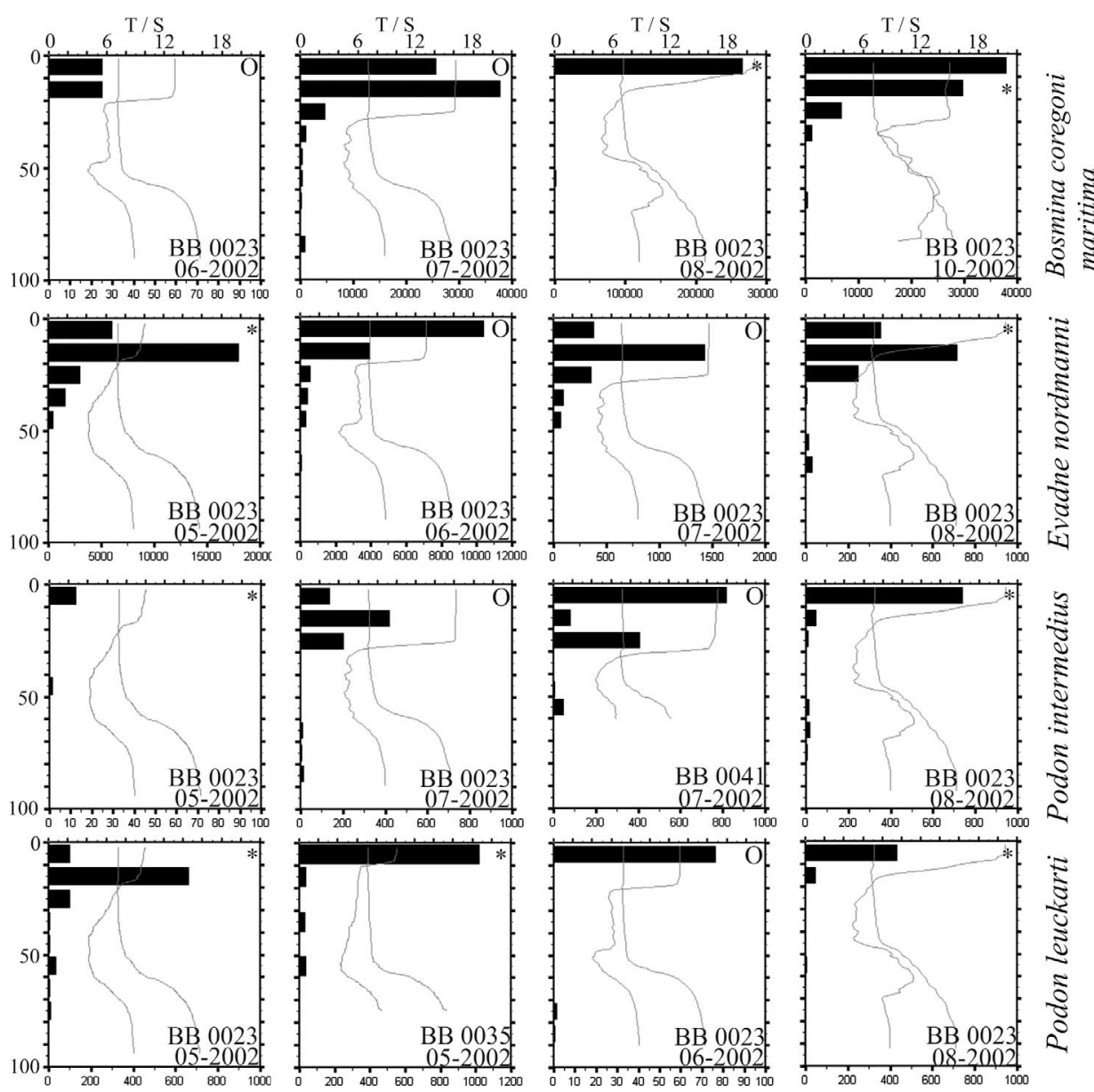

Fig. 8. Vertical distribution of Cladocerans. Note the different scaling. Day hauls are indicated by an open circle, night hauls by asterisk.

cope with the conditions in waters of the WINTER category when the thermocline is absent (see Figs. 4-6 and 7-9).

Quadrant II includes species mainly utilising water masses below the halocline.

Quadrant III includes taxa being present in the haline waters and those of the WINTER category, but show an obvious avoidance of warmer water masses in the Bornholm Basin.

Finally, quadrant IV represents taxa being dominant in the WINTER waters. They show a low affinity for more saline waters and an obvious avoidance of SUMMER waters.

In general, there was good agreement between CFSC values and depth-, season-, and/or stage-specific changes in the distribution of zooplankton observed in the Bornholm Basin (Figs. 4-9 and 10). The difference in depth preferences between species such as Acartia spp. that utilised waters above the halocline and Oithona similis that utilised waters below the halocline were clearly evident (Fig. 10). Ontogenetic differences in copepod water mass preferences were often reflected by differences in the CFSC values for $\mathrm{C} 1-\mathrm{C} 3$ and $\mathrm{C4}-\mathrm{C} 6$ stages of some species. For verification, taxa that wer located close to the separating hyperplanes and those having exceptional CFSC values were additionally evaluated (Figs. 11-13).

The CFSC values of the C1-C3 stages of $A$. bifilosa and A. longiremis were both close to the second root. The water mass plot (Fig. 11) illustrates that both utilised warm waters, while A. bifilosa showed higher counts in the SUMMER category, when temperatures were highest. In $T$. longicornis $\mathrm{C} 1-\mathrm{C} 3$ stages were dominant in the upper layers of the WINTER and SUMMER category, while high abundances of the C4-C6 stages were found deeper along the gradient between WINTER and HALINE. The former stages were also found in the remaining water masses of the SUMMER category when temperatures declined. In contrast, Pseudocalanus spp. were most prevalent in water masses of the HALINE category during the warm period. During winter they were also found in lower abundance in the $B B 60$ inflow waters.

Among the cladocerans $B$. coregoni maritima showed an outstanding CFSC loading on the second root. Here it can be clearly seen that the population mainly dwelled in the SUMMER waters and at the warmest temperatures (Fig. 12). Compared to B. coregoni maritima, the congener E. nordmanni tended to prefer SUMMER surface waters, but was not found in the warmest waters. The same was valid for the two Podon taxa, although P. intermedius attended to be found in warmer waters compared to P. leuckarti. During winter, populations declined and all cladoceran species were generally low. Respectively, cladocerans (as well as other taxa with the same characteristic) CFSC values indicate contribution towards numerical loadings for SUMMER waters.

Similar to E. nordmanni, larvae of Bivalvia mainly utilised the WINTER and SUMMER waters, but were not found in waters having the warmest temperatures (Fig. 13). The appendicularian Fritillaria sp. was found below the halocline during summer but it also utilised the waters of the WINTER category after the seasonal breakdown of the thermocline. Keratella spp. were only found during the warm season in remarkably high abundance. During that time, they were dominant in waters of the SUMMER category. When the thermocline disappeared, the remaining individuals were found in the remaining SUMMER and the adjacent WINTER waters. Dominant residing areas of Oikopleura sp. were the more haline water masses of HALINE during the warm season and the warm intermediate layer of the $B B 60$ 

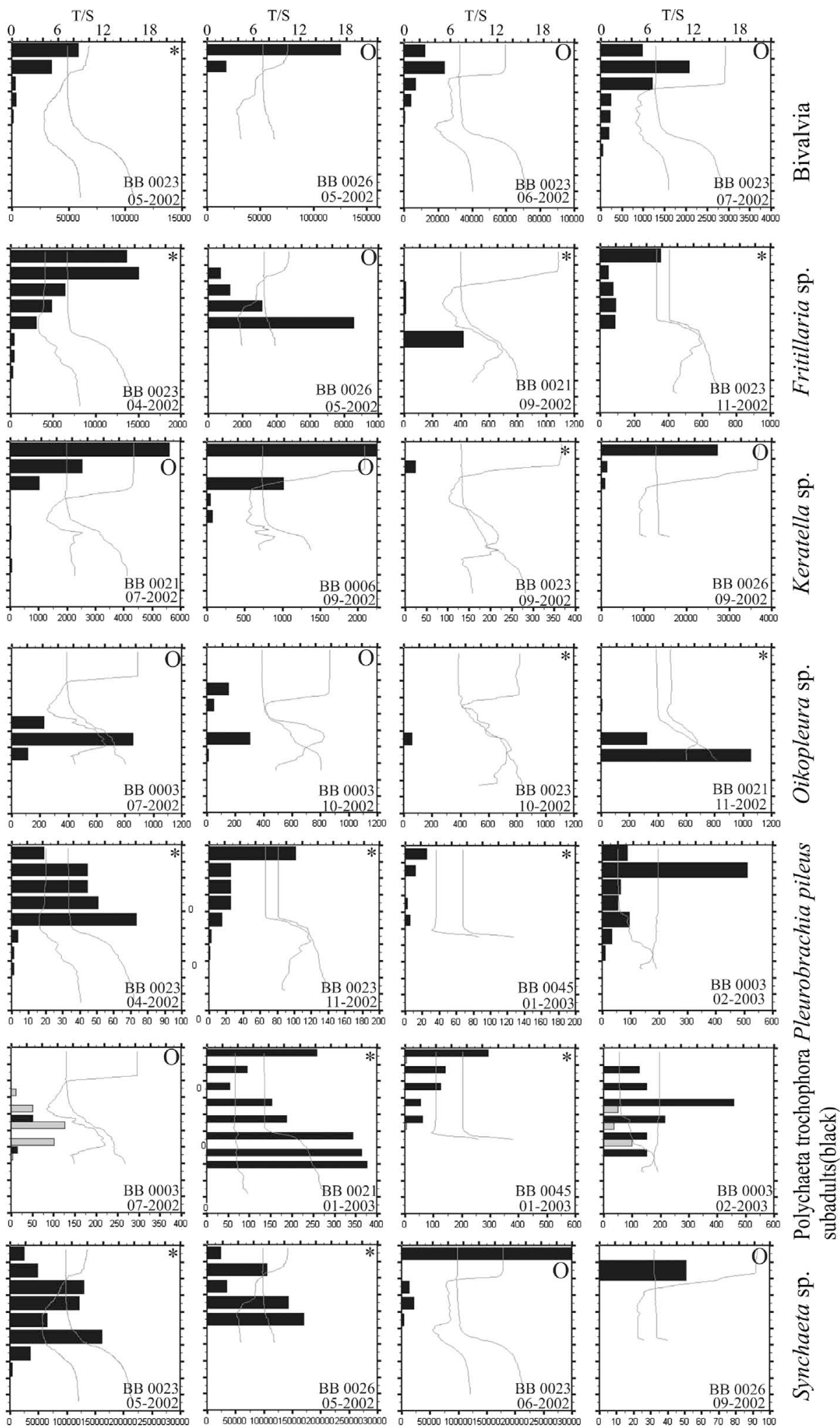

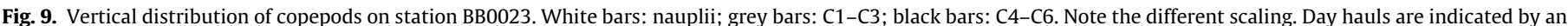
open circle, night hauls by asterisk. Acartia nauplii are pooled and are the same for both species.

waters during winter. Specimens of the Synchaeta spp. were mainly associated with the WINTER waters. During the transition period between stratified conditions and the breakdown of the thermocline, several specimens were found within the last remaining warm water lenses (see also Fig. 2).

\section{Discussion}

The GLOBEC-Germany field sampling campaign conducted in 2002 and 2003 represents one of the most thorough investigations of the zooplankton community in the Bornholm Basin, Baltic Sea 


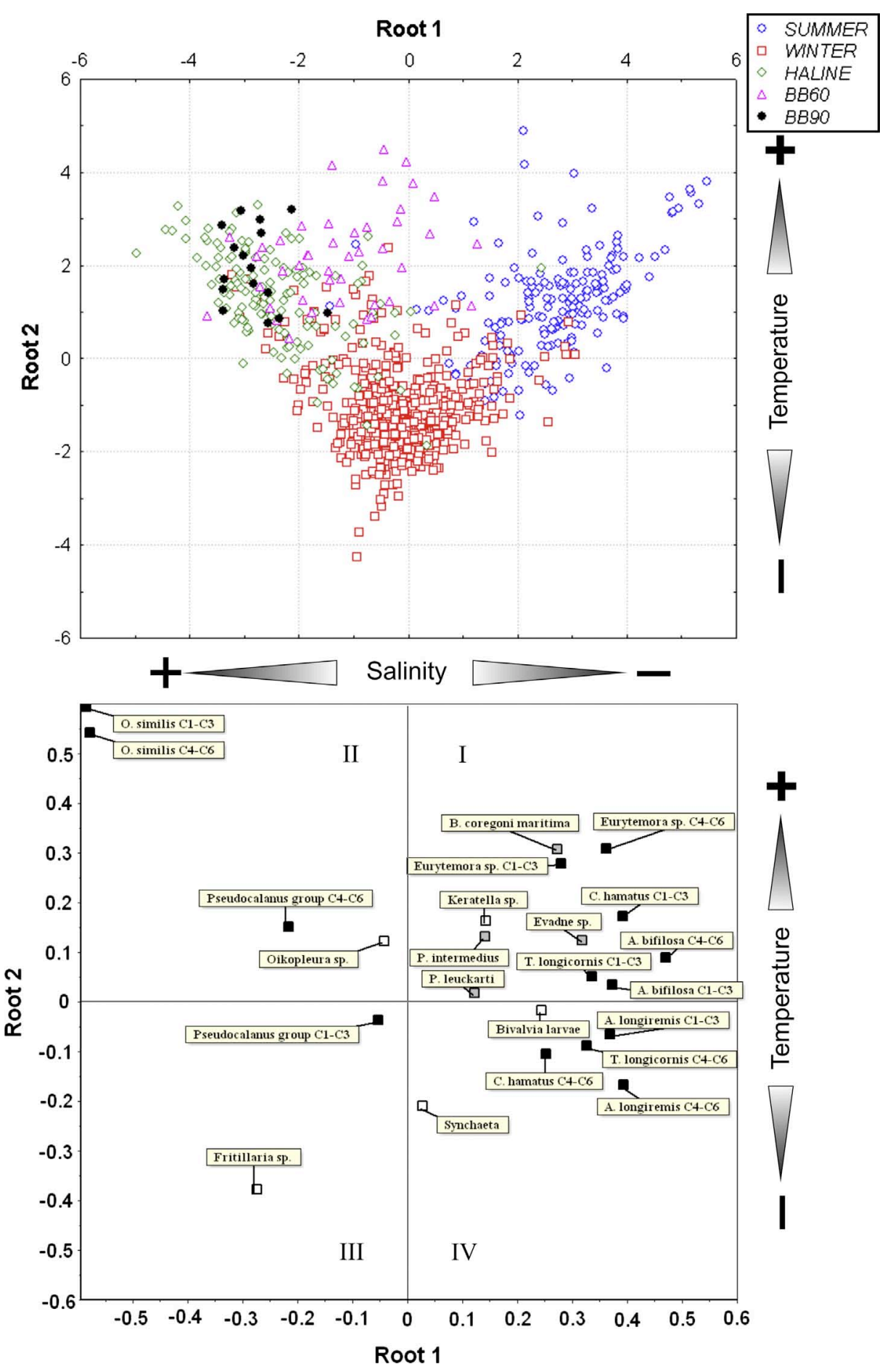

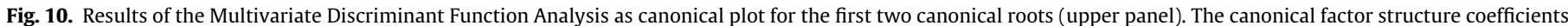
show the loadings of the species and developmental stages in the analysis. The quadrants can be assigned to different hydrographic conditions (lower panel).

that has been conducted in several decades. Thus, prior to examining depth-specific (water mass) habitat utilisation within the Bornholm Basin (our main aim of the present study), there is a need to thoroughly review previous reports of distribution and species composition of zooplankton taxa and briefly compare them with our observations. These comparisons are made with literature collected across the Baltic Proper (an area extending from the Danish Sounds and excluding the Åland Sea, Gulf of Finland and Gulf of Riga). In the next section, we provide this review (organized alphabetically by taxon) and, in later sections, we discuss the implica- tions of the results of our statistical analyses (MDFA and CFSC) for Baltic Sea zooplankton ecology and food web dynamics.

\subsection{Taxon synopses}

\subsubsection{Appendicularia}

Fritillaria borealis (LOHMANN) is considered oligotherm with a preference for temperatures $<10^{\circ} \mathrm{C}$ (Berrill, 1950; Ackefors, 1969) and a salinity range of 6-35 (Ackefors, 1969). In the Baltic Sea, it is usually abundant in May (with up to $350,000 \mathrm{n} \mathrm{m}^{-2}$ ), nearly 
Table 4

Classification matrix of the Multivariate Discriminant Function Analysis (MDFA).

\begin{tabular}{lcccccc}
\hline \multirow{2}{*}{ Observed } & Cum.\% & Predicted & & & \\
\cline { 2 - 7 } & & SUMMER & WINTER & HALINE & BB60 & BB90 \\
\hline SUMMER & 84.75 & 150 & 22 & 1 & 4 & 0 \\
WINTER & 91.48 & 12 & 419 & 26 & 1 & 0 \\
HALINE & 78.83 & 1 & 19 & 108 & 4 & 5 \\
BB60 & 47.73 & 3 & 3 & 17 & 21 & 0 \\
BB90 & 25.00 & 0 & 0 & 12 & 0 & 4 \\
Total & 84.37 & 166 & 463 & 164 & 30 & 9 \\
Wilk's Lambda & 0.088 & & & & & \\
F(92,3188) & 29.32 & & & & & \\
p-Level & $<0.001$ & & & & & \\
\hline
\end{tabular}

Table 5

Test for significance of the roots in the canonical analysis.

\begin{tabular}{lllrrrr}
\hline Root & Eigenvalue & Wilk's $\lambda$ & $\chi^{2}$ & DF & Cum.\% & $p$-Level \\
\hline 1 & 2.68 & 0.088 & 1982.17 & 92 & 60.2 & $<0.001$ \\
2 & 1.59 & 0.325 & 917.02 & 66 & 95.9 & $<0.001$ \\
3 & 0.16 & 0.842 & 140.84 & 42 & 99.5 & $<0.001$ \\
4 & 0.02 & 0.978 & 17.84 & 20 & 100.0 & 0.598 \\
\hline
\end{tabular}

Table 6

Means of the canonical variables in each root.

\begin{tabular}{lrrrr}
\hline & Root 1 & Root 2 & \multicolumn{1}{c}{ Root 3 } & \multicolumn{1}{c}{ Root 4 } \\
\hline SUMMER & 2.673 & 1.177 & 0.147 & -0.016 \\
WINTER & -0.117 & -1.117 & -0.044 & 0.014 \\
HALINE & -2.358 & 1.289 & 0.306 & -0.172 \\
BB60 & -1.174 & 2.165 & -1.487 & 0.127 \\
BB90 & -2.810 & 1.955 & 1.108 & 0.913 \\
\hline
\end{tabular}

absent between August and October, and avoids warm surface waters during summer (Hernroth and Ackefors, 1979). In the Mediterranean near Villefranche-Sur-Mer and in the Bay of Biscay $F$. borealis appears between December and January (Fenaux et al., 1998). Field observations and the CFSC values of the present study indicated that this species prefers haline waters and avoids warm surface waters; after the development of the thermocline $F$. borealis was mainly found below the halocline. The species was also abundant in the saline $B B 60$ inflow waters.

Oikopleura dioica (FoL) is considered to be the most common appendicularian in the Baltic Sea (Hernroth and Ackefors, 1979). It stays mainly in the deeper waters below the halocline (Ackefors, 1969 ) and reproduction depends on higher salinity $\geqslant 16.5$. In autumn, this species is often very abundant in Kiel Bight (Lohmann, 1899). Jespersen (1949) noted that $O$. dioica did not occur regularly from year to year in the Danish Isefjord and is mainly found from July to October with highest numbers in July. The abundance was not related to hydrographic conditions. Rasmussen (1973) found it in the Outer Broad of the Danish Isefjord from August onward, reaching highest values in August and October. Blanner (1982) noted rather large numbers in the Danish Limfjord in July, September and October. In the North Sea, the species can be found almost everywhere, having a distribution pattern similar to that of the copepod Paracalanus parvus (Krause et al., 1995). Our German GLOBEC results indicate that Fritillaria borealis was more abundant than Oikopleura dioica but not during the summer months when the abundance of the former species was particularly low. In contrast to $F$. borealis, $O$. dioica was found to dwell in higher salinity water masses, even those having higher temperatures ( $B B 60$ waters, Fig. 13).

\subsubsection{Bivalvia}

Five bivalves have been reported to be common in the Baltic Proper: Macoma baltica (L.), Cardium glaucum (BRUGUIERE), C. hauniense (PETERSEN \& RUSSEL), Mya arenaria (L.) and Mytilus edulis (L.) (Hernroth and Ackefors, 1979). The peak spawning period of $M$. edulis in the Baltic Proper has been reported to occur between $\mathrm{Au}-$ gust and October, with few larvae found in November. Larvae of the other species appear between May and August, at lower densities from September to April with a decreasing abundance gradient from the northwest to southeast (Hernroth and Ackefors, 1979). In Danish waters, the spawning of M. edulis starts in May and continues until July (Rasmussen, 1973). In the North Sea and the Danish Limfjord the maximum spawning time of most bivalve larvae has been reported to be from July to October (Rees, 1954; Rasmussen, 1973; Blanner, 1982) but the maximum abundance of larvae (from various species) is often highest in early July (Larsen et al., 2007). We have to assume, that our samples comprise a mixture of bivalve larvae of different species, the composition of which is subject to seasonal changes. Our GLOBEC Germany dataset suggested that larvae utilised low salinity waters and that bivalve larvae were most abundant in March/April. However, phenological patterns in our GLOBEC data are difficult to interpret since bivalve larvae were not determined to the species level. Nevertheless, general patterns suggest that the larvae encountered in our study avoid warm waters $\left(>15^{\circ} \mathrm{C}\right)$, as also revealed by the CFSC values.

\subsubsection{Cladocera}

With revision of the genus Bosmina, the subspecies Bosmina coregoni maritima (P.E. MÜLLER) is now included in the genus Eubosmina (e.g. Lieder, 1983; Taylor et al., 2002), however the former name has been used here for comparisons to other studies. Bosmina (Eubosmina) coregoni maritima is an endemic subspecies in the Baltic Proper, represents the only brackish water form of the species complex, and is more prominent in shallower areas (Purasjoki, 1958). This eurythermic and oligohaline species normally appears in April, later in the year than Evadne nordmanni (Eriksson, 1973b), after a threshold of a sea surface temperature of $2^{\circ} \mathrm{C}$ is reached. The population is small until waters warm to $15^{\circ} \mathrm{C}$, after which the species can be a dominant member of the zooplankton community (Hernroth and Ackefors, 1979). Warm temperatures are known to be suitable for this species (Ackefors, 1969) and some of the highest abundances on record for the Baltic were found in our German GLOBEC samples during a particularly warm period in August. The population rapidly declined in September and was absent from January to March in the water column. Stratified sampling indicated that more than $80 \%$ of the population existed above the thermocline (Hernroth and Ackefors, 1979). This was also found in our GLOBEC field sampling campaign. When most abundant, $B$. coregoni maritima occurred in the upper water layers during the warmest time of the year. The loadings of the CFSC captured this penchant for waters above the thermocline. In our open Baltic Sea samples, we found no clear evidence, that B. coregoni maritima was more abundant $\left(n \mathrm{~m}^{-3}\right)$ in surface waters at shallower stations.

Evadne nordmanni (Lovén) appears in the Baltic Proper regularly in April and May and is an important member of the zooplankton from the end of May to November, while only a few individuals can be found the rest of the year (Hernroth and Ackefors, 1979). Largest proportion of the population occurs in surface waters, but up to $\sim 25 \%$ may be found in cooler waters below $25 \mathrm{~m}$ in the Baltic Proper (Hernroth and Ackefors, 1979). Hence, it is the only cladoceran in the Baltic that tolerates higher salinities (Chojnacki et al., 1984). In the Baltic Proper, the abundance has been reported to decrease from south to north (Hernroth and Ackefors, 1979). In the Danish Limfjord, Kattegat, and North Sea, it has been recorded in the plankton from April to October (Gieskes, 1970, 1971a; 
Copepoda

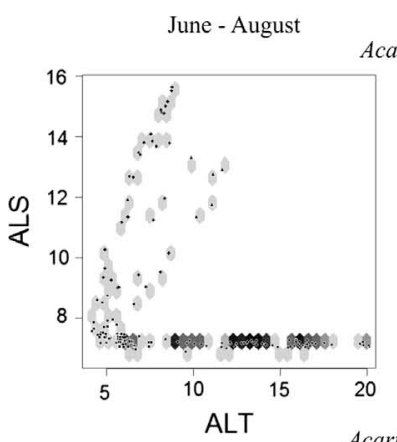

Acartia bifilosa $\mathrm{C} 1-\mathrm{C} 3$

November-March
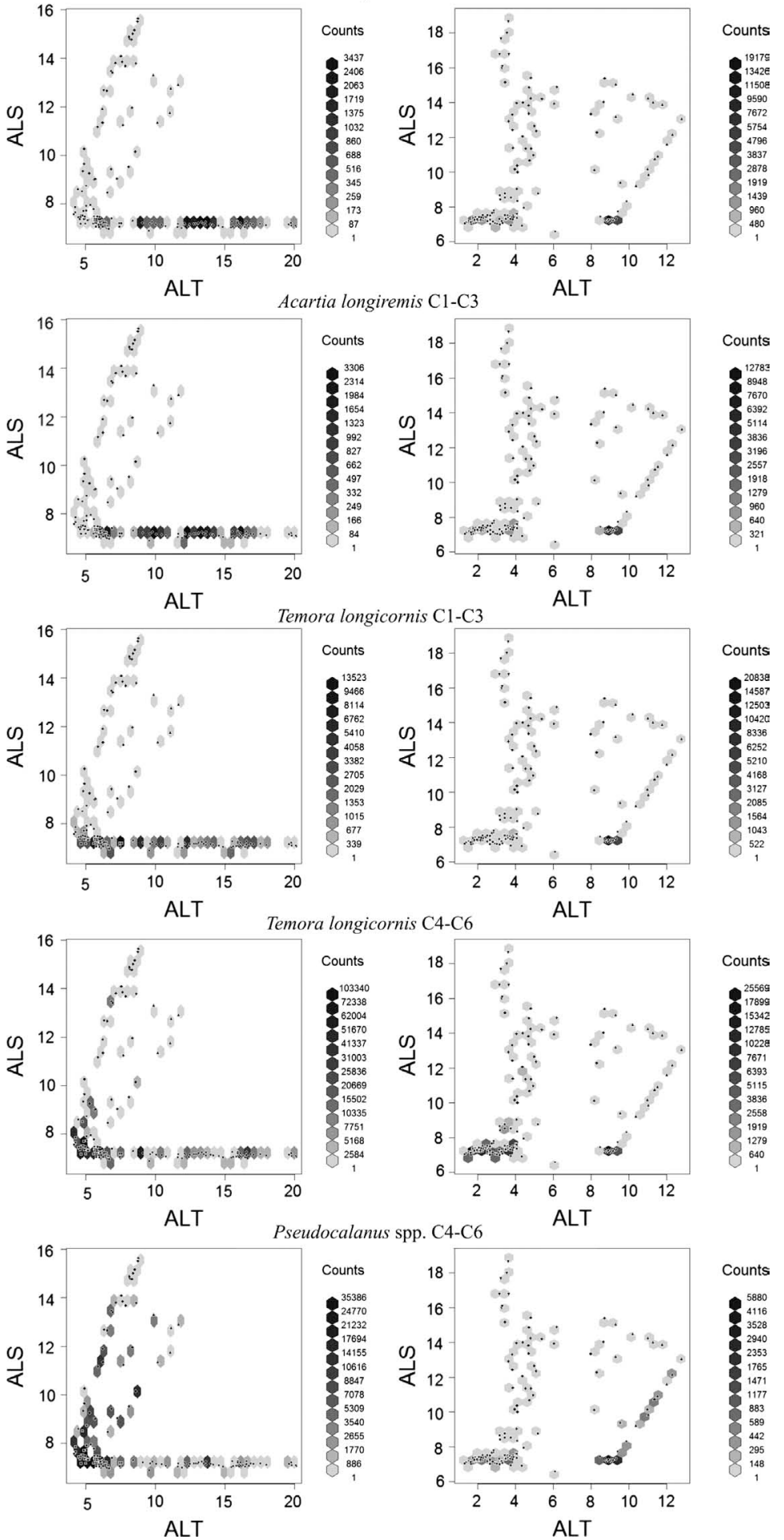

Counts

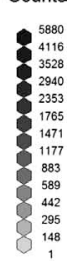

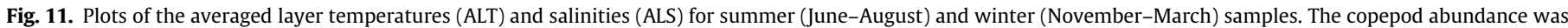

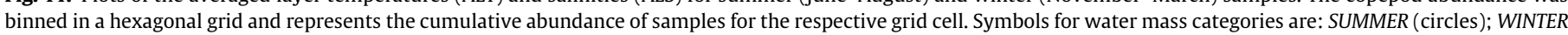
(squares); HALINE (diamonds); BB60 (upright triangles); BB90 (inverted triangles). Note different scalings.

Blanner, 1982). It is more abundant in the northern areas in the latter two regions (Hay et al., 1991). We found that E. nordmanni appeared earlier than Bosmina and that the abundance of $E$. nordmanni decreased during the time of peak abundance of Bosmina (the time of highest surface temperatures). Although the majority of E. nordmanni inhabited the SUMMER waters, this species tended to avoid the uppermost layer when SST was warmest. During the winter, this species inhabits the upper halocline likely seeking a warmer water refuge as CFSC loadings revealed no clear preference for higher salinity waters. It seems likely that 
Cladocera
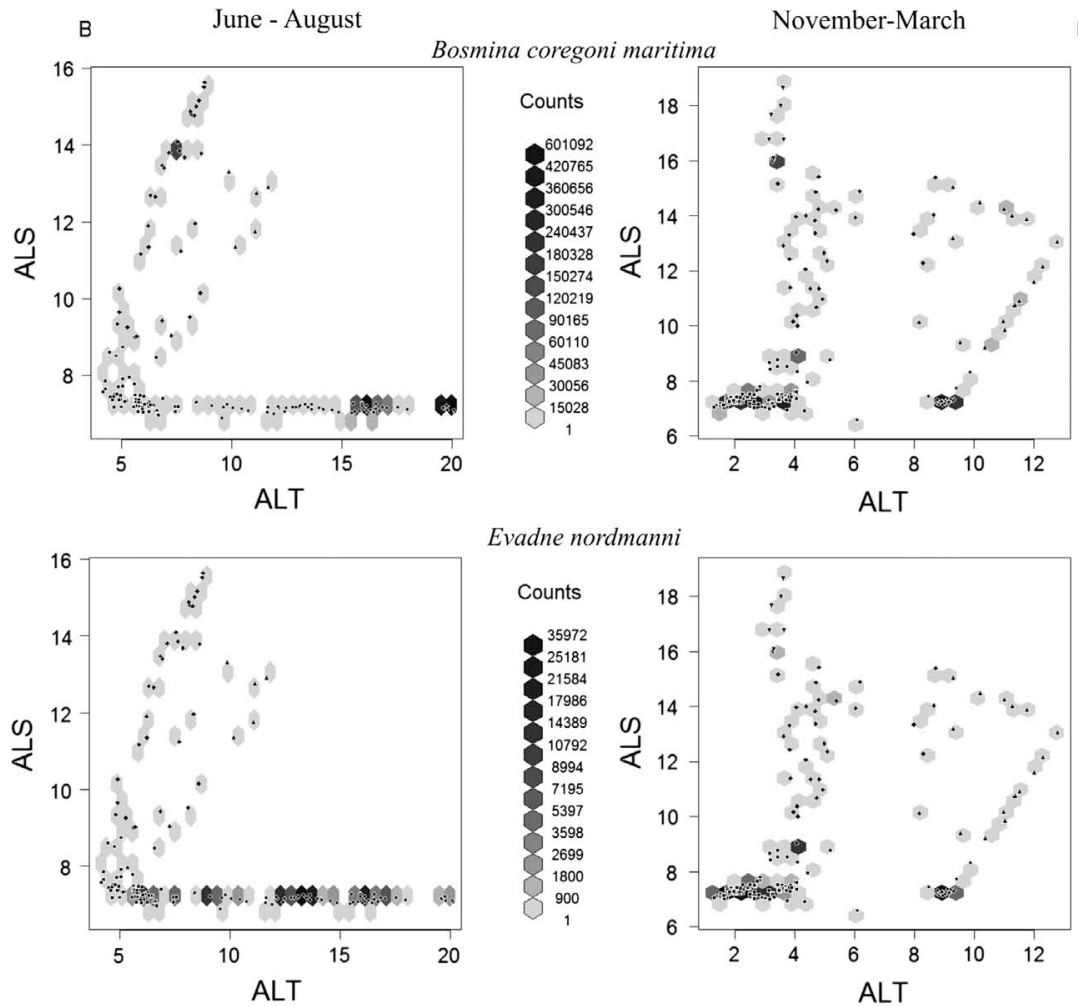

Evadne nordmanni
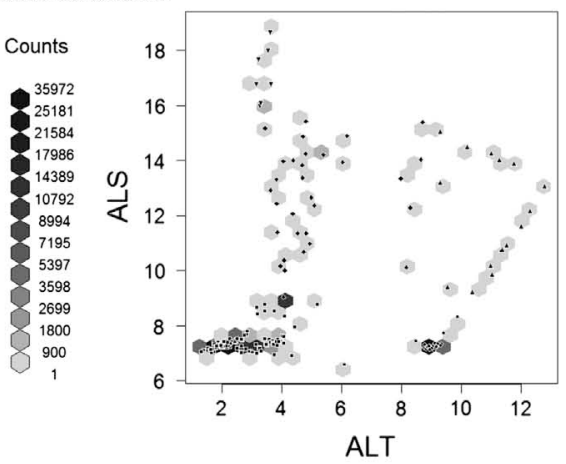

Counts

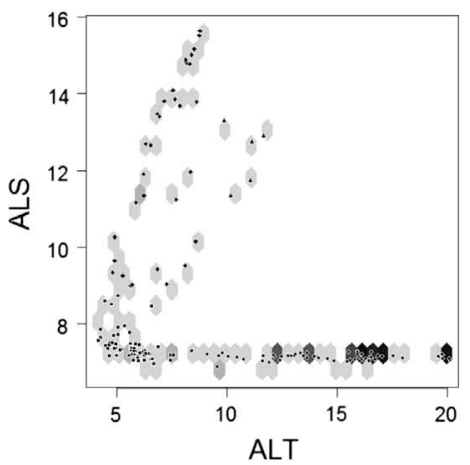

Podon intermedius
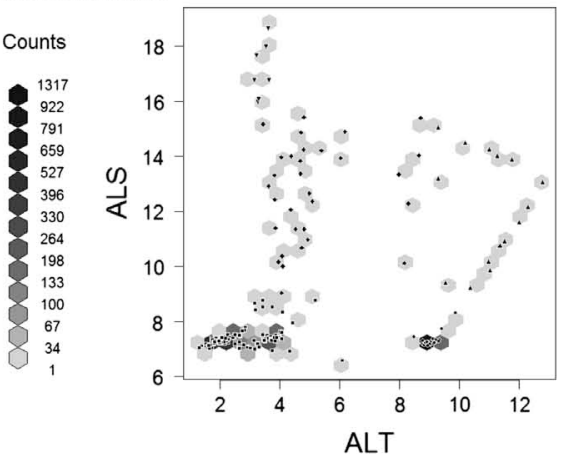

Counts

Podon leuckarti
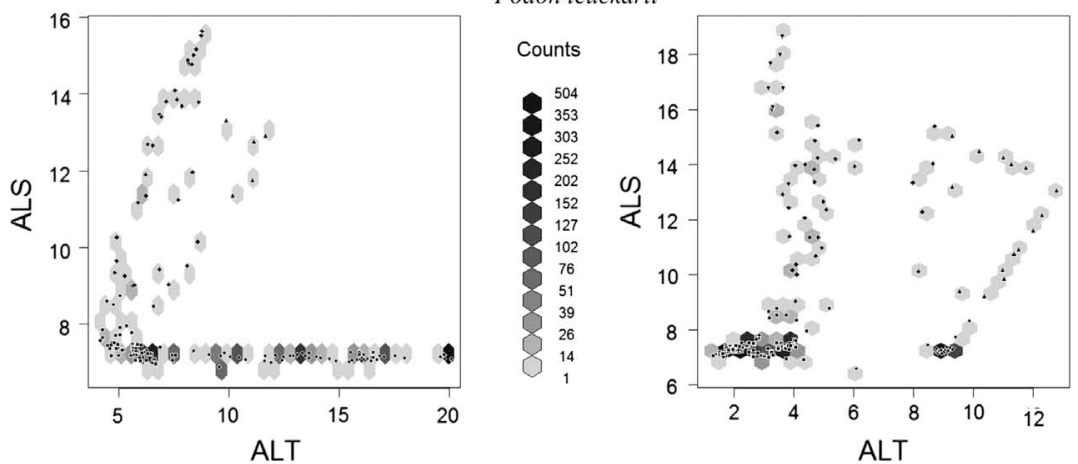

Counts

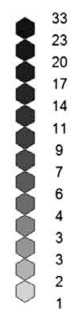

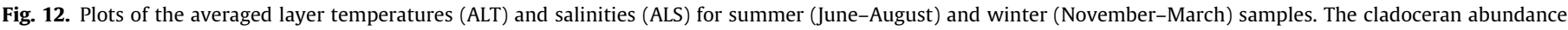

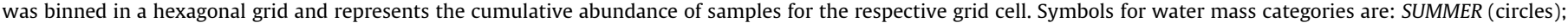
WINTER (squares); HALINE (diamonds); BB60 (upright triangles); $B B 90$ (inverted triangles). Note different scalings.

specimens take advantage of the slightly higher temperatures there.

The two most common Podon species in the Baltic Proper are Podon intermedius (LILLJEBorg) and Podon leuckarti (G.o. SARS) (Hernroth and Ackefors, 1979). The former is 1.2- to 1.4-times larger than the latter (Gieskes, 1971b). Podon intermedius occurs at low abundance across all regions of the Baltic Proper and first appears in June (Hernroth and Ackefors, 1979). In Danish waters, the first individuals have been reported to appear in July in the Kattegatt, reaching their peak maximum abundance about 1 month later 


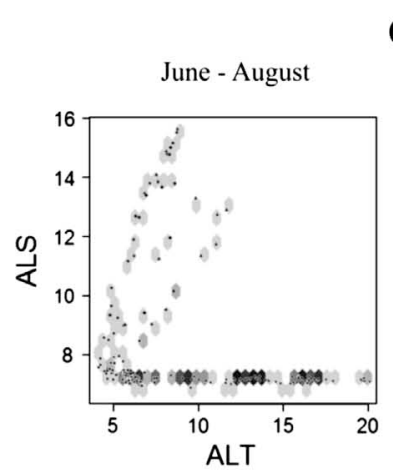

\section{Other taxa}
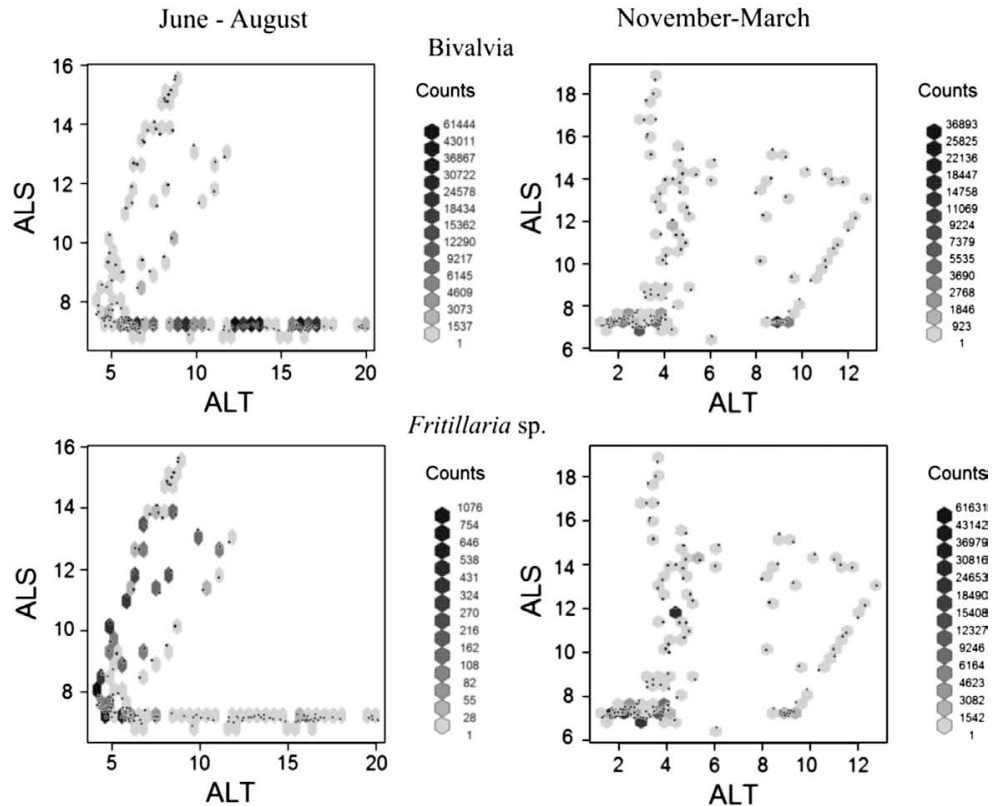

Fritillaria $\mathrm{sp}$
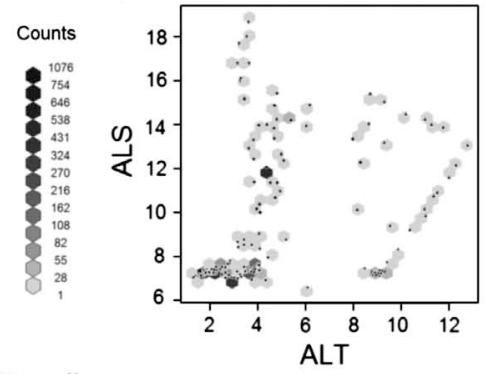

Counts

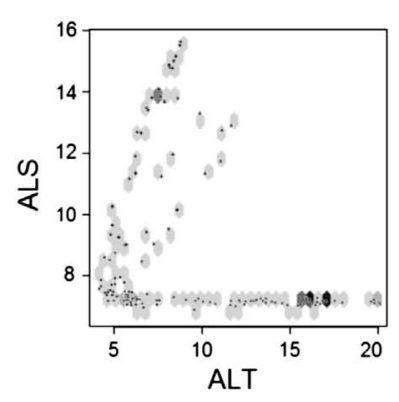

Keratella spp.
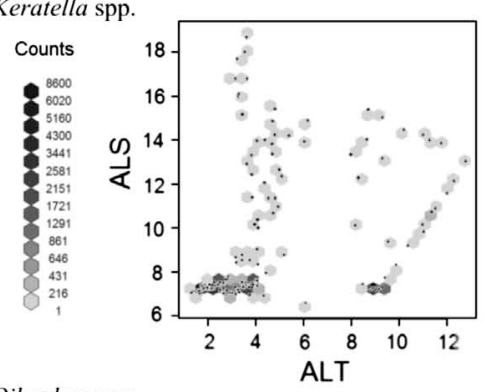

Counts

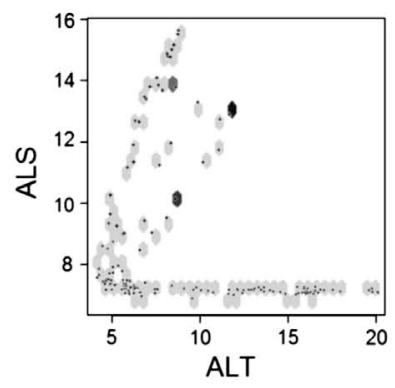

Oikopleura $\mathrm{sp}$
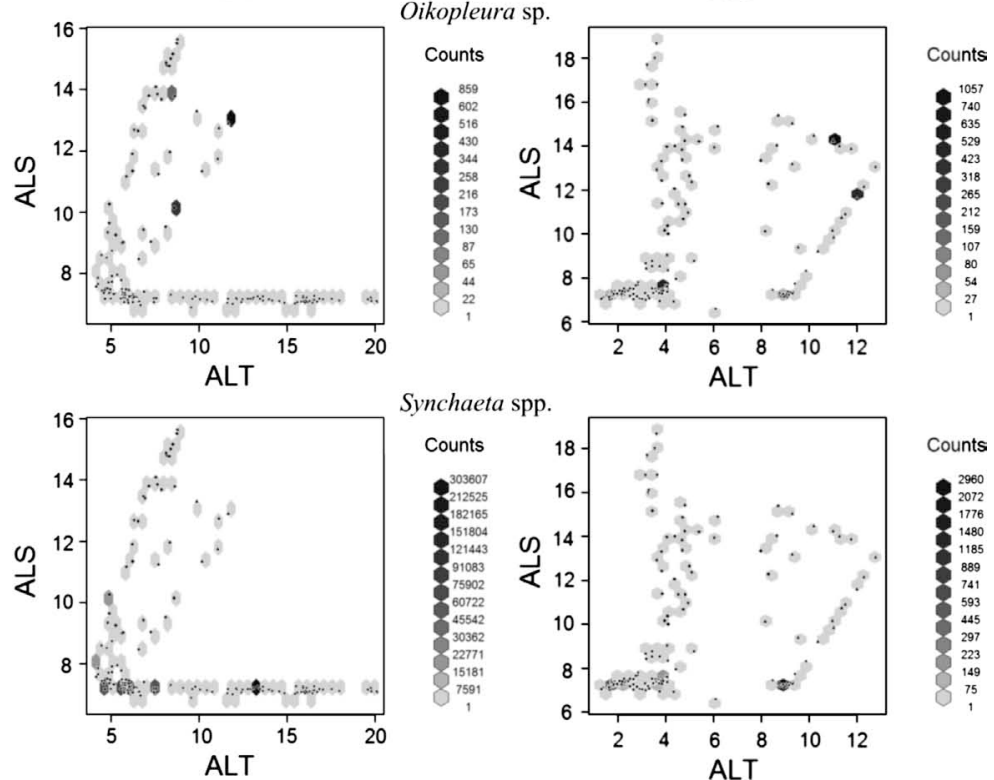

Synchaeta spp.
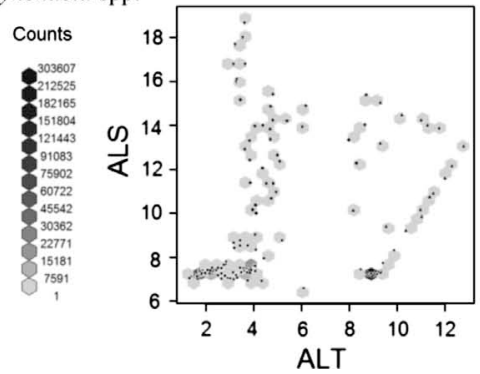

Counts

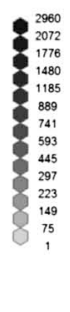

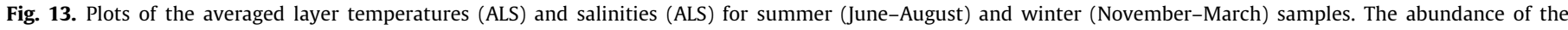

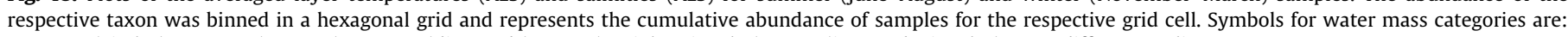
SUMMER (circles); WINTER (squares); HALINE (diamonds); BB60 (upright triangles); BB90 (inverted triangles). Note different scaling.

(Eriksson, 1974; Gieskes, 1971b), while they are few in August in the Öregrund Archipelago (Eriksson, 1973b). In the North Sea, this species does not appear prior to June, reaches its peak abundance in August and September, and is more abundant in the eastern regions (Gieskes, 1971a). Podon intermedius requires warmer tem- peratures than $P$. leuckarti and populations of the former and latter start to increase at $\sim 9.5^{\circ} \mathrm{C}$ and $6.5^{\circ} \mathrm{C}$, respectively. Podon leuckarti is a neritic, stenohaline, and stenothermal cladoceran (Ackefors, 1969) that is scarce in marine waters of the North Sea where it occurs in highest abundance from 12 to $13^{\circ} \mathrm{C}$ (Gieskes, 
1971a). It is dominant there up to the end of June, when egg-carrying females appear. Our GLOBEC sampling indicated that P. leuckarti peaked earlier than $P$. intermedius, supporting the differences in temperature dependent development reported by the aforementioned authors. Furthermore, the CFSC indicated that $P$. intermedius has a higher affinity for warmer surface waters than $P$. leuckarti, which clearly preferred lower temperature surface waters.

\subsubsection{Copepoda}

According to Ackefors (1969), the copepods Acartia bifilosa (Giesbrecht) and Acartia longiremis (Lilljeborg) are the most common Acartia congeners of the deeper basins of the Baltic Sea. They appear to breed all the year round in the Baltic Proper, having maximum naupliar abundance in February-March and November (Hernroth and Ackefors, 1979). Both species are widespread over the Baltic Proper and their nauplii are often not distinguishable from one another (Hernroth and Ackefors, 1979). Acartia bifilosa prefers the lower salinity (brackish) waters and thus is common in the Baltic Sea (Ackefors, 1969) and European estuaries. Laboratory experiments suggest that its vertical distribution depends more on temperature than on salinity (Lance, 1962). In the Bothnian Sea (northern Baltic), the species can be quite abundant in August with peaks in naupliar abundance in June (Eriksson, 1973b). Here, the field observations and CFSC values suggest that both the younger and the older copepodite stages of $A$. bifilosa prefer the warmer surface layers after the thermocline developed.

Acartia longiremis has been reported to be more abundant than Acartia bifilosa in the southern Baltic Proper (Hernroth and Ackefors, 1979). It is a euryhaline and oligothermal species (Ackefors, 1969), but is rare in the North Sea. In the Atlantic, this species is found in deeper water layers in more southern latitudes (Jespersen, 1940) as well as in subpolar waters around Greenland and within Norwegian fjords, avoiding warm surface layers. With increasing temperatures and strengthening of the thermocline, we observed that later-staged $A$. longiremis copepodites and adults (C4-6) prefer the intermediate (WINTER category) waters between the thermoand halocline (Figs. 7 and 10).

Centropages hamatus (LILLJEBORG) is abundant in temperate-boreal waters (Eriksson, 1973c) and tolerates a wide range of salinities (Blanner, 1982). It is a mesothermic, euryhaline species that is distributed mainly in the northern Atlantic and adjacent seas (Jespersen, 1940) and appears to dynamically shift its thermal tolerance range to match local/regional conditions (Halsband-Lenk et al., 2002). In the Baltic Sea, it is most abundant between 15 and $50 \mathrm{~m}$, living on the edge of its low salinity tolerance (Ackefors, 1969). It has been commonly found from the Gotland Basin (Ackefors, 1969) to the Kattegat and in the North Sea (Eriksson, 1973a, 1973c). Previous studies suggest that it disappears from the water column in October (Hay et al., 1991) and overwinters as resting eggs (Engel and Hirche, 2004). In contrast, C. hamatus has been reported to be captured all year round in the Danish Limfjord with highest abundances in June (Blanner, 1982). In the southern Baltic Proper it has been reported to be abundant above the thermocline, but not in the northern Baltic. Our analyses showed that older stages seem to avoid the warmest waters. After the breakdown of the thermocline, all stages of the remaining $C$. hamatus population continued to dwell in the upper mixed waters above the halocline.

The taxonomy of the genus Eurytemora is not finally clarified. While some authors report E. affinis, E. hirundoides and E. hirundo from the Baltic Sea (Lindquist, 1959), Gurney (1931) considers E. hirundoides to be a form of $E$. affinis. It is often the dominant species in the estuaries of rivers and fjords in the Baltic Sea and other estuarine and brackish waters (Arndt and Heidecke, 1973; Hirche, 1992). In the Öregrund Archipelago (Swedish coast), E. affinis is the most important species, with low abundances in June/July that increase in August (Eriksson, 1973b). It has been described as an eurythermic and oligohaline species (Ackefors, 1969) and produces resting eggs (Ban and Minoda, 1989). The temporal appearance during our study is congruent with earlier findings. As the brief peak in abundance coincided with the $B B 60$ inflow from the North Sea, it is possible that specimens were transported within these waters to our study area, although North Sea origin is unlikely. It is also possible that the exceptional temperatures of the BB60 inflow induced a temperature signal causing the hatching of resting eggs. However, this is unlikely due to the simultaneous occurrence of peak values of all life stages (nauplii, C1-C3, and C4-C6) suggesting that a mature population was advected to the Bornholm Basin. Additionally, CFSC values for Eurytemora spp. underline the occurrence of this copepod above the thermocline in October and in the upper mixed waters after the breakdown of the thermocline (Figs. 4, 7 and 10).

The cyclopoid Oithona similis (cLAUS) is a boreal, euryhaline, and eurythermal species that is common in both neritic and oceanic regimes (Nielsen and Sabatini, 1996). It is a well known member of the zooplankton community in the Baltic Sea (Ackefors, 1969), North Sea, Skagerrak, and Kattegatt (Blanner, 1982). In the Baltic, it experiences sub-optimal conditions and its horizontal distribution is closely related to the circulation regimes of deep waters as described by Hansen et al. (2004). Those authors did not detect diel vertical migration likely due to a threshold, set up by a low salinity tolerance of $\sim 7$ (Ackefors, 1969). In the Bornholm Basin, this species is found in deep waters where the salinity is $\geqslant 14.5$ (Ackefors, 1969). Similarly, the species prefers more saline waters within the Danish Limfjord (Blanner, 1982). Due to its small body size, standard sampling gears (with large mesh sizes) most likely under-sample its abundance (Rae and Fraser, 1941; Colebrook et al., 1961; Krause et al., 1995). Our GLOBEC sampling confirmed the association of this species with high salinities. This copepod showed the most clear preference for water masses below the halocline, although C1-C3 stages were sometimes observed within this layer.

As previously mentioned, it is difficult to distinguish among Pseudocalanus spp. (BоECK) and Paracalanus parvus (CLAUS). Thus, Gran et al. (1936) recommended the combination of these groups. Rae and Rees (1947) also included Microcalanus pusillus. Recent findings within the GLOBEC Germany program indicate that $P$. acuspes, $P$. elongatus, and $P$. parvus can be found within the same samples but that samples mainly consisted of Pseudocalanus acuspes (Renz and Hirche, 2006; Grabbert et al., 2010). We pooled all of these individuals within the Pseudocalanus group. Copepods within the Pseudocalanus genus are well known euryhaline and oligothermic species in the Baltic Sea (Ackefors, 1969). In the North Sea, Pseudocalanus spp. usually occur in the southern areas and have been reported to be most common in autumn and winter (Rae and Rees, 1947). Outside shelf seas, this species normally occurs near the coasts and is rare in the central northern Atlantic, where it is found in deeper waters at lower latitudes (Jespersen, 1940). In our study, ontogenetic differences were observed in the Pseudo-Paracalanus spp. group, suggesting that older copepodites inhabit waters below the halocline while younger stages occur in shallower depth strata when waters are relatively cold.

Temora longicornis (P. MÜLLER) is an euryhaline and mesotherm species that is common in temperate and coastal seas (Jespersen, 1940). It is a common member of the zooplankton community in the southern Baltic Proper between April and September and is most abundant from July to September (Ackefors, 1969; Hernroth and Ackefors, 1979). Previous studies in the Baltic reported that individuals were only found above the thermocline during the night in the summer, while they had a more even depth distribution during the rest of the year (Hernroth and Ackefors, 1979). The species occurs at the lower end of its physiological tolerance 
to salinity in the Baltic Sea (Hernroth and Ackefors, 1979; Viitasalo et al., 1995; Holste et al., 2009) where $>90 \%$ of the population resides above the halocline (Dutz et al., 2010). The CFSC values of the canonical analysis and field observations indicate that the C4-C6 copepodites are predominantly associated with the winter water below the thermocline, while the younger $\mathrm{C} 1-\mathrm{C} 3$ stages also utilise warmer waters. Seasonal changes in water mass utilisation, particularly those related to changes in the strength of the thermocline, tended to also be well described by the CFSC.

A great deal of research has been conducted during the German GLOBEC program that augment the seasonal and depth-specific copepod data presented in this study. Most of these, process-oriented studies have been conducted to understand the life cycle strategies and abiotic and biotic factors affecting the patterns of abundance and distribution of specific species. These species included Acartia longiremis, Temora longicornis and Pseudocalanus acuspus (Peters et al., 2006; Renz et al., 2007; Dutz et al., 2010) due to their trophodynamic importance as prey items for German GLOBEC target fish species (see Peck et al., this volume; Voss et al., this volume). For example, the field data presented in this study and additional measurements of development and egg production rates of Pseudocalanus acuspes suggested very long generation times ( 1 year) and potential food limitation of egg production after May for this species (Renz et al., 2007). Diet studies indicated that Pseudocalanus acuspes displays opportunistic feeding with later developmental stages being linked to the microbial loop (Peters et al., 2006; Renz et al., 2007). Work on Temora longicornis by Dutz et al. (2010) suggested that spring development of this species relies on a complex interaction among prevailing temperatures, spring phytoplankton bloom dynamics, and post-bloom feeding conditions. Cold temperatures sustained a slowly growing overwintering generation in the Bornholm Basin. A marked delay in springtime production of Temora in 2003 compared to 2002 was likely due to food limitation of the first generation in May 2003, a year having a relatively early spring bloom in March followed by rapid warming (Dutz et al., 2010). Feeding studies performed on this species also revealed a strong effect of spring bloom dynamics, specifically the importance of diatoms during time periods of high reproduction and energy accumulation (Peters et al., in press). Finally and in contrast to these other two copepod species, the factors driving the observed population dynamics of Acartia longiremis in the Bornholm Basin are still not well understood, particularly the overwintering and potential utilisation of resting eggs by this species (Peters, 2006; Peters et al., 2007).

\subsubsection{Ctenophora}

Of the ctenophores traditionally encountered in the Baltic Sea, Pleurobrachia pileus (O.F. MÜLLER) is an euryhaline and oligothermic species (Ackefors, 1969). Its larvae have been reported to be most abundant from February to May in cold waters having a narrow range in salinities (6-8), according to Hernroth and Ackefors (1979). In another stratified system, the Black Sea, this species is found in deeper layers and in the hypoxic zone down to the upper boundary of the anoxic $\left(\mathrm{H}_{2} \mathrm{~S}\right)$ zone (Mutlu and Bingel, 1999; Kideys and Romanova, 2001). GLOBEC sampling confirmed the seasonal timing of abundance in Pleurobrachia pileus in the Baltic Sea where this species was most abundant in April (2002) and February (2003).

\subsubsection{Polychaeta (Subadults and trochophora)}

Polychaete larvae are abundant in the Baltic Proper, are more numerous at greater depths, and avoid warm surface waters in summer (Hernroth and Ackefors, 1979). The trochophore larvae develop into polychaeta larvae prior to switching to benthic life. Deeper areas can only be recolonised when dissolved oxygen concentrations are sufficiently high which depends upon water exchange processes (Leppäkoski, 1971, 1975). We found polychaeta to be most abundant after the inflow events and there was a clear increase in the year 2003. Since January 2003, polychaeta were common also in the deepest layers of the basin likely in response to the higher dissolved oxygen concentrations in deep waters in 2003 compared to 2002 (Fig. 2).

\subsubsection{Rotatoria}

Acccording to Ackefors (1969) and Hernroth and Ackefors (1979), the genus Keratella is represented by four species (K. eichwaldi, K. platei, K. quadrata, K. recurvispina) in the Baltic Sea. In contrast, more recent investigators report a much higher number of species (Telesh et al., 2009). These rotifer species are found in the warm surface layers and are abundant from July-November and encountered most frequently in September (Hernroth and Ackefors, 1979). The genus Synchaeta is represented by six species (S. baltica, S. curvata, S. fennica, S. gyrina, S. monopus, S. triophthalma), with $S$. baltica and $S$. monopus being the most common (Ackefors, 1969; Hernroth and Ackefors, 1979). The CFSC support the field observations that rotifers of the Keratella genus avoid water layers below the halocline and also utilise the warm surface waters.

Members of the Synchaeta genus are abundant throughout the Baltic Proper and can be particularly abundant between May and July with values of about $1,000,000 \mathrm{~m}^{-2}$ in June/July (Hernroth and Ackefors, 1979). In these months, Synchaeta spp. can make up $20-80 \%$ of all individuals in a net haul. The onset of increasing abundance is coupled to the hatching of resting eggs (Hernroth and Ackefors, 1979). These rotifers are located both above and below the thermocline in waters between 8 and $16^{\circ} \mathrm{C}$ (Ackefors, 1969; Hernroth and Ackefors, 1979). The abundance of Synchaeta spp. in our 2002 GLOBEC-Germany samples (Fig. 6) was much higher than the values reported by Hernroth and Ackefors (1979) for the Baltic Proper likely because the time of appearance coincided more closely with the time period of our field survey. Since the highest abundance occurred prior to the development of the thermocline, the CFSC assigned Synchaeta spp. to the WINTER category, although specimens seem to tolerate temperature up to $12{ }^{\circ} \mathrm{C}$ in the Bornholm Basin.

\subsubsection{Scyphomedusa}

Medusae of Aurelia aurita (L.) are generally found all over the Baltic proper (Hernroth and Ackefors, 1979; Möller, 1980a). In Kiel Bight (Western Baltic Sea) ephyrae and/or medusae were observed throughout the year (Möller, 1980b). In the Bornholm Basin, was only found from July to January and at highest abundance between August and November (Janas and Witek, 1993). The species is mostly distributed in the upper $20 \mathrm{~m}$ of the water column (Margonski and Horbowa, 1995; Lischka, 1999).

Cyanea capillata (L.) is found throughout the Baltic Sea up to $59^{\circ} \mathrm{N}$ and is mainly distributed in the deep offshore areas (Hernroth and Ackefors, 1979; Möller, 1980a). The population depends upon transport via advection from higher salinity areas of the Baltic Sea or from the North Sea (Möller, 1980a; Gröndahl and Hernroth, 1987). In the Bornholm Basin, C. capillata is only sporadically encountered and, in years when it occurs, the timing of its first appearance is highly variable (February-August). The species is typically not observed above $40 \mathrm{~m}$ and is normally much less abundant than A. aurita (Janas and Witek, 1993; Hernroth and Ackefors, 1979; Margonski and Horbowa, 1995; Lischka, 1999). Our GLOBEC sampling indicates that, similar to A. aurita, the successive inflows may have caused the earlier appearance of $C$. capillata (Barz et al., 2006).

Our GLOBEC-Germany studies indicated that Aurelia aurtita medusae were at their highest abundance and were distributed throughout the Bornhom Basin in August and early September 

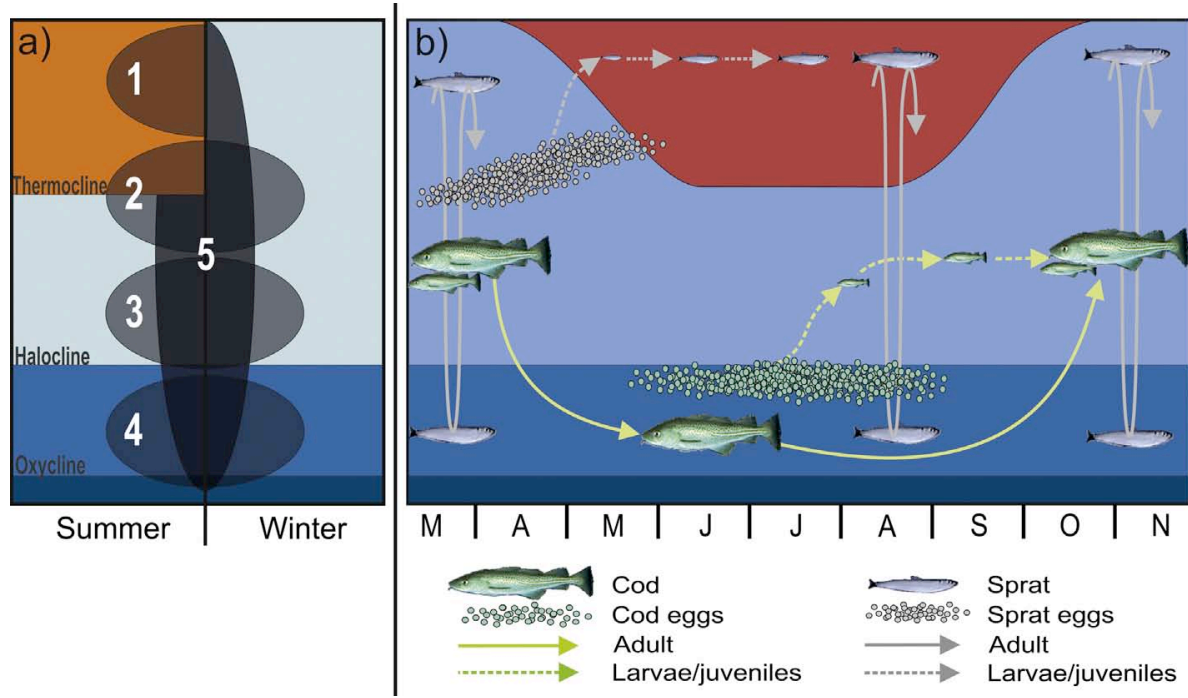

Fig. 14. (a) The different utilisation modes which zooplankton species are assigned to and (b) the spatial overlap of the zones with the dominant fish species.

2002 (see Barz and Hirche, 2005). In 2003, ephyrae were found in April and the first, small medusae appeared in May (Fig. 6 and see Barz et al. (2006)). Successive inflow events in 2003 may have caused the earlier arrival of Aurelia aurita in the Bornholm Basin. No vertical migration was observed in the medusae of this species (Barz and Hirche, 2005) and hydrodynamic drift modelling suggested that a large part of the population observed in the Bornholm Basin originated from source areas in the western Baltic Sea such as Kiel Bight (Barz et al., 2006). In 2003, the first Cyanea capillata medusae were caught earlier, in May (Fig. 6 and Barz et al., 2006) and the abundance was higher in July and August compared to 2002. The medusae of Cyanea capillata were much less abundant than those of Aurelia aurita. Patterns of seasonal and depth-specific abundances of the medusae in the Bornholm Basin of the genus Cyanea and Aurelia are discussed in greater detail by Barz and Hirche (2005) and Barz et al. (2006).

\subsection{Dominant modes of habitat utilisation by zooplankton in the Bornholm Basin}

Within stratified systems such as deeper Baltic Sea basins, understanding how physical forcing and changes in climate-driven factors affect trophodynamic processes demands that speciesspecific patterns of spatial distribution are thoroughly investigated. In brackish systems such as the Baltic Sea, the strength of interaction among different trophic levels (e.g., ecosystem functioning) is dictated, to a large extent, by physiological constraints affecting the distribution of the zooplankton community. We statistically analysed the 832 samples collected during the GLOBEC Germany program to reveal the dominant patterns in habitat usage among groups. Statistically significant patterns were found using MDFA and CA (Fig. 10) suggesting that water masses can be distinguished, to a high degree of certainty, by differences in their zooplankton composition (when a sufficient sampling resolution is chosen). Although exclusive residence within a single habitat category (water mass) was rare, the CA helped reveal habitat categories that were most preferred by different species. Habitat preference is presumably an active process representing physiological tradeoffs between tolerance limits to key abiotic factors (Pörtner, 2010) and the availability of prey, resources and the behavioural tactics (e.g., avoidance) in light of predator risks.

Our findings suggest that depth-specific differences in hydrographic factors (e.g., the interaction between temperature $(T)$, salinity $(\mathrm{S})$ and oxygen $\left(\mathrm{O}_{2}\right)$ ) are one of the strongest mechanisms structuring habitat utilisation by the zooplankton community in the Bornholm Basin. Our community-level analysis identified distinct depth layers that were established by the combination of hydrographic conditions that changed seasonally due to strength of atmospheric forcing. The observed patterns in this study agree well with differences in vertical distribution of single species/taxa previously reported for Baltic Sea zooplankton (e.g. Ramner, 1930; Berrill, 1950; Ackefors, 1969; Gieskes, 1970, 1971a, 1971b; Eriksson, 1974; Hernroth and Ackefors, 1979; Blanner, 1982; Ojaveer et al., 1998; Mutlu and Bingel, 1999; Schulz et al., 2007; Schulz and Hirche, 2007). However, the higher spatial and vertical resolution and the large number of species in our data set allow us to move beyond merely discussing ramifications of depth-related changes in key factors to single species and to provide a more general description and classification of the spatial structure of the zooplankton community in response to the unique hydrographic layering. The observed modes in distribution of zooplankton species can be perceived as habitats having different $T \times S \times \mathrm{O}_{2}$ combinations and being separated by clines.

The results of the MDFA suggested five different utilisation modes (Fig. 14a, Table 7). The first three modes are associated with waters above the halocline and were further distinguished by the presence or absence of a thermocline and seasonal changes in the abundance of species.

Mode I was characterised by species that were mainly present during the warmer months in the surface layer. After the thermocline was established, all stages of Eurytemora sp., Bosmina coregoni maritima and Podon intermedius were most abundant in this water layer (SUMMER category) but were more or less absent the rest of the year. These species utilise resting eggs as an overwintering strategy, allowing life cycle persistence. The most important species describing this mode was $B$. coregoni maritima, although the abundance of this species declined by early September 2002, when surface temperatures were still high.

Mode II included species that prefer warmer temperatures but that can also persist in the absence of the thermocline in slightly cooler waters (WINTER and SUMMER categories). This mode was characterised by all copepodite stages of Acartia bifilosa and the C1-C3 stages of Centropages hamatus and Temora longicornis.

Mode III includes species present throughout most of the year but that do not utilise the warm surface layer. Their habitat is mainly comprised of WINTER waters. All copepodite stages of Acar- 
Table 7

The spatio-temporal utilisation modes as revealed by MDFA and species specific observations.

\begin{tabular}{|c|c|c|}
\hline Pattern & Distribution range & Species \\
\hline \multirow[t]{3}{*}{1} & \multirow[t]{3}{*}{$\begin{array}{l}\text { Species being mainly abundant during warm periods in waters of the SUMMER category } \\
\text { Tempo-spatially restricted by } T \text { (high) and } S \text { (low) }\end{array}$} & $\begin{array}{l}\text { Cladocera } \\
\text { Bosmina coregoni maritime } \\
\text { Evade nordmanni } \\
\text { Podon intermedius }\end{array}$ \\
\hline & & $\begin{array}{l}\text { Copepoda } \\
\text { Eurytemora } \mathrm{C} 1-\mathrm{C} 3 \\
\text { Eurytemora } \mathrm{C} 4-\mathrm{C} 6\end{array}$ \\
\hline & & $\begin{array}{l}\text { Rotatoria } \\
\text { Keratella spp. }\end{array}$ \\
\hline \multirow[t]{3}{*}{2} & \multirow{3}{*}{$\begin{array}{l}\text { Species being abundant for long times of the year in the categories SUMMER and WINTER } \\
\text { Spatially restricted by } S \text { (low) }\end{array}$} & $\begin{array}{l}\text { Bivalvia } \\
\quad \text { Bivalvia larvae }\end{array}$ \\
\hline & & $\begin{array}{l}\text { Cladocera } \\
\quad \text { Podon leuckarti }\end{array}$ \\
\hline & & $\begin{array}{l}\text { Copepoda } \\
\text { Acartia bifilosa } \mathrm{C} 1-\mathrm{C} 3 \\
\text { Acartia bifilosa } \mathrm{C} 4-\mathrm{C} 6 \\
\text { Centropages hamatus } \mathrm{C} 1-\mathrm{C} 3 \\
\text { Temora longicornis } \mathrm{C} 1-\mathrm{C} 3\end{array}$ \\
\hline \multirow[t]{2}{*}{3} & $\begin{array}{l}\text { Species being abundant for long times of the year, but restricted to the category WINTER } \\
\text { Spatially restricted by } T \text { (low) and } S \text { (low) }\end{array}$ & $\begin{array}{l}\text { Copepoda } \\
\text { Acartia longiremis C1-C3 } \\
\text { Acartia longiremis C4-C6 } \\
\text { Centropages hamatus C4-C6 } \\
\text { Temora longicornis C4-C6 }\end{array}$ \\
\hline & \multirow{3}{*}{$\begin{array}{l}\text { Species being mainly present in the category HALINE } \\
\text { Spatially restricted by } S \text { (high) }\end{array}$} & $\begin{array}{l}\text { Rotatoria } \\
\text { Synchaeta spp. }\end{array}$ \\
\hline \multirow[t]{2}{*}{4} & & $\begin{array}{l}\text { Appendicularia } \\
\text { Oikopleura dioica }\end{array}$ \\
\hline & & $\begin{array}{l}\text { Copepoda } \\
\text { Oithona similis C1-C3 } \\
\text { Oithona similis C4-C6 } \\
\text { Pseudocalanus spp. C4-C6 }\end{array}$ \\
\hline \multirow[t]{2}{*}{5} & \multirow{2}{*}{$\begin{array}{l}\text { Species being present in the category WINTER and HALINE } \\
\text { Spatially restricted by } T \text { (low) }\end{array}$} & $\begin{array}{l}\text { Appendicularia } \\
\text { Fritillaria borealis }\end{array}$ \\
\hline & & $\begin{array}{l}\text { Copepoda } \\
\quad \text { Pseudocalanus spp. C1-C3 }\end{array}$ \\
\hline
\end{tabular}

tia longiremis, C4-C6 of Centropages hamatus C4-C6 and Temora longicornis, as well as Synchaeta spp. could be assigned to this mode. Most were highly abundant in May 2002 after the development of a strong thermocline. Mechanistic explanations for this distribution pattern likely include slightly lower and higher temperature and salinity preferences, respectively (Jespersen, 1940; Halsband-Lenk et al., 2002; Holste et al., 2009) and the utilisation of dimly lit regions to help avoid predation in the summer when young clupeids are abundant in the upper water layers (e.g. Voss et al., 2003; Dickmann et al., 2007).

Mode IV included species that mainly utilised the water mass beneath the halocline (the HALINE category) that was only available at deeper stations. Species characteristic for this mode are Oikopleura dioica, all stages of Oithona similis and Pseudocalanus sp. C4-C6 as well as trochophore larvae. While the latter two species had higher abundance in strata with cold temperatures, $O$. dioica was often found in saline and warm waters and had its peak abundance during the time of the $B B 60$ inflow. The ability of $O$. similis to reside year-round in deeper waters is likely due to this species' ability to tolerate lower oxygen concentrations due to its relatively low rates of respiration (Castellani et al., 2005), particularly in those cold water masses during stagnant inflow periods and is present all year round.

Mode $\mathbf{V}$ includes species that can utilise both low and high salinity waters but avoid the warm surface layer. Thus, these species are mainly abundant in WINTER and HALINE waters. Fritillaria borealis, Pseudocalanus sp. C1-C3 and subadult polychaetes dis- played this distribution and had the highest abundance during the colder months.

A similar investigation was conducted on a subset of the data presented here for a single, deep station in the centre of the Bornholm Basin (BB0023; Schulz et al., 2007). The results of the present study suggest that the zooplankton community structure found at the shallow edges of the Bornholm Basin can also be well described based upon hydrographic characteristics. Thus, this conceptual classification seems to be applicable on the scale of the Bornholm Basin. Although most species could be clearly assigned to a single mode in the present study, the distribution of others was obviously more complex. The brackish environment of the Baltic Sea forces many species to live under sub-optimal, osmotic conditions with the halocline forming an important barrier between fresher surface waters and deeper more saline waters. Additionally, strong seasonal differences in water temperature are found, particularly in the upper water layer and the interaction between halo- and thermoclines (and phytoplankton production) causes complex vertical gradients in habitat suitability. The five modes described above were based upon a static, pre-defined discrimination of water masses that were applied to all taxa. It seems obvious, that species specific temparuture thresholds for ascending/desending to different water masses in the Baltic may slightly differ. However, in these cases, knowledge of the life history strategies of specific species can be used to augment our interpretation of habitat utilisation based solely on statistical analyses. There are five cases that we briefly discuss in the following: 
(1) Bivalve larvae mainly utilised the SUMMER waters, but seemed to avoid the warmest, upper water layers. The same appears to be the case for the two cladoceran species $E$. nordmanni and P. leuckarti, which were most abundant when the thermocline started to become established or was dissipated. While Bivalve larvae and $P$. leuckarti abundances decreased in later summer the stock of Evadne nordmanni persisted and was present in significant numbers until the end of the warm season (including a second peak when surface temperatures decreased). Within the SUMMER category the temporariloy decreasing E. nordmanni stock (with the presence of $\sim 15^{\circ} \mathrm{C}$ water, see Figs. 8 and 12) seems to invade strata closer to and in the thermocline from July on, maybe as a response to the high surface temperature. Therefore, it seems appropriate to assign E. nordmanni to mode I, while P. leuckarti and Bivalve larvae should be seen as mode II taxons.

(2) Categorising all copepodite stages as either early (C1-C3) or late (C4-C6) may ignore relevant, ontogenetic changes in vertical distribution or differences between males and females. This applies at least to the C1-C3 stages of Pseudocalanus sp. (Renz and Hirche, 2006), where our analysis suggested mode $\mathrm{V}$ waters were the best habitat.

(3) An analysis on the same data set used here indicated that diel vertical migration (DVM) occurred only in A. longiremis and T. longicornis (Schmidt, 2006) and, as the samples used for the analyses were taken during the day and night, DVM might have influenced the results. However, DVM appears to be reduced in the Baltic Sea compared to other systems (e.g. Titelman and Fiksen, 2004; Schmidt, 2006). During summer, the depth centroid of $T$. longicornis was calculated to be $20 \mathrm{~m}$ at night and $60 \mathrm{~m}$ during the day, which mainly represents WINTER category waters. On the other hand, $A$ longiremis performed DVM in the depth range of the thermocline (Schmidt, 2006). Both of these species were not abundant in the uppermost layer during the summer, when surface waters were warmest. Therefore, assignment of these species based upon ambient $T$ and $S$ to mode III, might be a simplification ignoring the ultimate causal factors influencing their vertical distribution.

(4) Fritillaria borealis is thought to be a glacial relict species that is capable of utilising lower salinity surface waters. During summer, the distribution of $F$. borealis extends deeper into more haline waters where a layer of cool intermediate winter water exists (Schulz and Hirche, 2007). At those depths, the pycnocline tends to accumulate prey within size classes utilised by F. borealis (Lande and Wood, 1987; MacIntyre et al., 1995; Vallin and Nissling, 2000). Hence $F$. borealis may also be responding to clines in prey abundance.

(5) The period during which Keratella spp. abundance was highest extended somewhat prior to and after the persistence of the SUMMER water mass category. The early beginning of this stratification occurred at a colder temperature than that chosen for the threshold for the SUMMER category. Thus, it can be suggested that Keratella spp. should be seen as a summer species and assigned to mode I.

\subsection{Limitations of the habitat classification approach}

Although our results demonstrate characteristic zooplankton assemblages within different hydrographic layers and/or different seasons, there are some potential issues that should be discussed. First, the analysis required the creation of nominal categories based upon prevailing hydrographic conditions in the respective depth ranges where samples were collected. However, there is inherent variability in zooplankton species composition and abundance at smaller scales than those sampled in the present study (e.g. Young et al., 2009). Such variability can result from a variety of physical features of the habitat such as internal waves that commonly occur in stratified waters (Banse, 1964). In the direct vicinity of discontinuity layers, discernable differences in vertical community structure could be more subtle. Second, it is possible that some depth layers were not sampled as efficiently as others (e.g., net clogging in certain layers due to blooms) or that the gear more effectively captured some species as opposed to others. These are inherent weaknesses of most broad-scale zooplankton surveys employing nets.

The problem of different spatial scales between sampling and relevant environmental features has been previously discussed by Steele (1989) and, in the present study, this spatial mismatch is apparent in our high-resolution CTD measurements (resolution $1 \mathrm{~m}$ or less) that needed to be averaged due to the coarser resolution $(10 \mathrm{~m})$ multinet hauls. In some situations, the assignment of areas based upon averaged $T$ and $S$ thresholds will not accurately reflect the hydrographic situation encountered by zooplankton within that depth layer. For instance, when a boundary between two categories was found within the $10 \mathrm{~m}$ sampling intervals, the higher proportional share of the recorded ambient hydrography determined which category was assigned. In this case the sample contains species compositions from two categories in proportional shares. If the assumption that the zooplankton community assemblage is characteristic for a given hydrographic layer holds true, then the abundance-based classification will match the a priori classification. Thus, the classification matrix (Table 4) is a direct proxy for category-wise hypothesis testing. The main categories SUMMER, WINTER and HALINE consistently obtained high classification rates ( $>78 \%$ ). Misclassifications (Table 4 ) among these three categories partially arise from the proportional mixing of species/categories that was just discussed.

On the other hand we were not able to clearly distinguish among waters of the categories HALINE, BB60 and BB90. There is an obvious reason of this; these water masses are all characterised by relatively high salinity that is required by a couple of organisms. The high misclassification rate among these three categories was most likely due to the similar species composition which caused these waters to be merged with the HALINE category. In this case, the category with the highest number of a priori assignments becomes a reference class. This is most obvious in BB90 samples where classification success was only $25 \%$ and all other samples had the highest probability of belonging to the HALINE category. No false positives were observed among BB60 and BB90 (Table 4). While BB90 samples showed good canonical congruence with the HALINE category (Fig. 10, upper panel), BB60 samples were more variable due to exceptional thermal conditions and likely differences in species composition "up stream" (at the origin of this inflow water). In any case, the overall probability of single samples belonging to one of the pre-defined categories was calculated based on the dominant species composition, which allows a proper discrimination.

Although we observed several inflow events during our sampling campaign, the typical situation is a two- or three-storeyed system. Within the deep basin, high saline waters are captured in the troughs, covered by waters of lower salinity. These low saline waters are further divided during summer, when the surface waters heat up due to the input of solar energy and the thermocline defines a boundar. Predators, as well as prey, have to cope with these fundamental conditions. Set up by tolerance levels in their physiological capabilities specimens utilise different parts of the water column.

\subsection{Physical forcing and habitat structuring}

Hydrography in the Baltic Sea is related to local wind fields and sea level pressure, both of which are subject to variability in atmo- 
spheric forcing as evoked by changes in the North Atlantic Oscillation (Lehmann et al., 2002). Water mass exchange with the North Sea has decreased during the last decades as a consequence of the prevailing atmospheric conditions. This, in turn, has reduced the renewal of saline waters into deep basins and increased the freshwater runoff from rivers decreasing Baltic salinity (Matthäus and Frank, 1992; Matthäus and Schinke, 1994). During periods of stagnation between inflow events, deep water conditions deteriorate and degradation processes form an anoxic layer close to the seafloor which restricts the available habitat for zooplankton and other organisms. Given the same halocline depth, the volume of suitable habitat below the halocline is smaller at shallower stations (e.g. Hansen et al., 2004; Schmidt et al., 2003). These changes in abiotic factors have reduced the reproductive volume for Pseudocalanus and have been correlated with the decrease in Pseudocalanus spp. stocks (Möllmann et al., 2003). In 2003, after the major Baltic inflow, species assigned to mode IV would benefit from increases in the volume of suitable, deep water habitat. Thus, Major Baltic Inflows (MBIs) improve conditions for Pseudocalanus spp. (Renz and Hirche, 2006) as well as Oithona similis (Hansen et al., 2004) and allow re-colonisation of benthic areas that were previously uninhabitable (Leppäkoski, 1971, 1975; Laine et al., 1997). After the completion of MBIs, decomposition processes decrease the dissolved oxygen concentration and, once again, begin decreasing the suitable habitat volume for these species. Due to vertical mixing processes, salinity and nutrients increase within upper water layers (Fonselius, 1970). Thus, MBIs can alter habitat characteristics throughout the water column.

Direct effects of inflow events on the species composition of Bornholm Basin zooplankton via advection of populations from the North Sea (e.g. Postel, 1996) or responses of resident zooplankton to warming seem likely as peaks in abundance of most copepods and some other taxa were observed between September and November 2002 (BB60 \& BB90 events). During this time period, waters within the halocline $(B B 60)$ had the highest temperatures due to the inflow of North Sea water that was captured within the trough of the Basin. An example of the latter would be the hatching of resting eggs of Centropages hamatus, Temora longicornis, and Acartia spp. in response to warming temperatures (Engel and Hirche, 2004; Dutz et al., 2004). The advection of polychaete larvae seems possible but would not explain the time shift between larvae and earlier (trochophore) life stages in January/February 2003. Thus, higher abundances of polychaete larvae may be an indicator of the temporary improvement of deep water conditions. The successive inflow events of 2003 were also associated with an earlier arrival of $A$. aurita and $C$. capillata to the Bornholm Basin (Barz et al., 2006). Comparison of abundance data with a circulation model suggested that a large portion of the A. aurita population observed in the Bornholm Basin originated from coastal areas of the western Baltic Sea such as Kiel Bight (Barz et al., 2006). Finally, it appears that some species that were advected into the study region within mid-waters were able to migrate to their preferred mode (e.g., Eurytemora spp. in surface waters). In summary, the temporal changes in the zooplankton community composition that occurred during the inflows highlight the strong coupling that exists between physical processes occurring in surface and bottom waters and responses of the zooplankton community. The complex interactions that are induced by changes in water temperature are often less obvious and just allow to consider that changes appear (e.g. Roemmich and McGowan, 1995). Anyhow, advected specimens seemed to migrate to their preferred mode.

Long-term changes in $T$ and $S$ during the last decades induced a shift towards more oligohaline species such as the endemic Bosmina coregoni maritima. During summer, warm temperatures allow B. coregoni maritima to outgrow competitors and predators by par- thenogenetic reproduction (Viitasalo et al., 2001) and this species becomes the most abundant one of the upper water layers. Up to $87 \%$ of the diet of Aurelia aurita consisted of this cladoceran, but populations of Aurelia were too small to exert predatory control of the Bosmina population (Barz and Hirche, 2005). Decreases in MBIs (and/or climate change) has resulted in warmer water temperatures that have increased the productivity of Acartia spp. (Möllmann and Köster, 2002) and their importance in the Baltic Sea food web.

One of the most important physical factors influencing vertical habitat structure is the interplay between wind stress and solar heating. The upwelling displacement of the thermocline due to surface wind stress is inversely proportional to stratification and increases with increasing temperature (Gill, 1982). This mechanism likely causes the formation of a shallow, strong thermocline such as that observed during the calm summer of 2002 and other years with similar conditions. The shallow thermocline reduces the volume of this warm water habitat. A strong thermocline can also prevent mixing and nutrient exchange which reduces primary production (Roemmich and McGowan, 1995). Mechanisms that limit prey resources and decrease habitat volumes can affect zooplankton community structure via various mechanisms including increased niche competition and other intra-guild dynamics (Holt and Polis, 1997) and increased targeting of zooplankton by predators (predator-pit concept) (Bakun, 2006) by increasing prey density within narrowing preferred habitats that decrease predatorprey distances. Although causal processes are unknown, the steep and shallow thermocline observed during August 2002 was associated with a lower abundance of copepods and less phytoplankton fluorescence in the warm surface waters (D. Mengedoht, AlfredWegener-Institute, personal communication).

\subsection{Ecological consequences of zooplankton vertical habitat partitioning}

The modes of zooplankton habitat utilisation identified in the present study can be conceived as zooplankton groups that have similar life history strategies and that likely compete with each other for resources. This results in a concept similar to the definition of guilds (Root, 1967) and is of importance for a variety of different processes. Beside a direct impact on the food web structure, it bears implications for theoretical ecology and modelling aspects. Taxa sensitive to warmer temperatures are expelled from shallow areas during periods of strong thermo-stratification. This stable stratification reduces vertical mixing and excludes species in modes III and IV for longer periods from surface waters and processes therein. Avoidance of low salinity waters is the mechanism that is likely responsible for the grouping of species in mode IV. In this case the inhabitable volume is lower at shallower sites when the halocline is close to the seabed or absent (e.g. Hansen et al., 2004; Schmidt et al., 2003) and utilisation of shallow areas is only possible when the halocline elevates/shoals. During inflow events, saline waters from the North Sea cascade over the shallow sills. After inflow events, species assigned that were assigned to mode IV in the present study have been found in greater abundance in more eastern parts of the Baltic Sea in previous studies (e.g. Mankowski, 1951). Previous studies utilising depth-integrating nets often reported changes in horizontal distribution (e.g. Ackefors, 1969; Hernroth and Ackefors, 1979) that were likely due to changes in the availability of depth-specific water masses (e.g., relative differences between the depths of the halocline and sea bottom, and seasonal changes in the strength of the thermocline described above).

Species categorised in mode IV may also suffer reduced population mixing in the Baltic Sea. The southwest to northeast environmental gradient in surface waters, from marine conditions in the 
Skagerrak towards nearly fresh waters in Bothnian Bay and Gulf of Finland, respectively, also exists (albeit to a lesser extent) in deeper waters (Bonsdorff, 2006). The sills are shallower than the halocline and form natural barriers to the movements of saline deep waters and associated zooplankton taxa. Genetic differences between southwest and northeast Baltic populations of herring (Clupea harengus L.) have been reported (Jørgensen et al., 2005). Thus, the less mobile, topographically-separated zooplankton species in mode IV would also be prime candidates for genetic isolation among basins. Interestingly, Baltic populations of Pseudocalanus acuspes, an Arctic relict species found in mode IV (taxa restricted to deep, cold, saline waters), appears to have lost considerable amounts of genetic diversity compared to conspecifics in specific marine systems (e.g., Holmborn et al., 2011). This loss of genetic diversity makes it challenging to find evidence for further genetic isolation. As an aside, the losses of genetic diversity may lead to reductions in the adaptive capacity of the Pseudocalanus group (namely $P$. acuspes and potentially other mode IV species) to cope with the climate-driven warming and freshening projected for the Baltic Sea.

The vertical separation of zooplankton in different modes translates into vertical heterogeneous (patchy) distributions of potential prey items for zooplanktivorous fish and invertebrates (Fig. 14b). Zooplankton taxa within the different modes will, thus, experience markedly different spatial overlap with potential predators and, therefore, suffer different magnitudes of mortality and top-down regulation. As a corollary, calculating selection-indices for predators do not necessarily reflect active behaviour but spatial heterogeneity of prey distribution in relation to the preferred depth of a predator. Field data obtained during GLOBEC-Germany on clupeids and scyphomedusae such as the vertical habitat utilisation and zooplankton diets (Barz and Hirche, 2005; Bernreuther, 2007; Peck et al., this volume), confirm the conceptual modes of zooplankton habitat utilisation developed in the present study. In the following, we briefly discuss the potential roles of gelatinious (syphomedusae) and fish (clupeid) as potential competitors/predators with/ on zooplankton with respect to depth specific habitat utilisation and abundance of zooplankton.

In 2002, patterns of occurrence of scyphomedusae were congruent with that of most copepods and Bosmina coregoni maritima, but medusa abundance was relatively low. Additionally, a seasonal and vertical mismatch with eggs and larvae of dominant fish species was observed in the Bornholm Basin. For these reasons, medusae had negligible effects in terms of predation or competition for food with larvae, and resulted in nearly no impact on the zooplankton community (Barz and Hirche, 2005). Earlier appearance of medusa in 2003 resulted in a longer temporal overlap, but again they exerted low rates of predation and competition due to their low abundance.

As opposed to the weak trophodynamic effects of scyphomedusae, clupeid fish, such as herring (Clupea harengus) and sprat (Sprattus sprattus) can consume large amounts of zooplankton and have been reported to exhibit top-down control of their prey in the Baltic Sea (Arrhenius and Hansson, 1993). Acartia spp. and T. longicornis are major components of the diet of clupeids (Möllmann and Köster, 2002; Casini et al., 2004). The recruitment success of fish, particularly Baltic cod (Gadus morhua) and sprat that spawn in deep basins of the Baltic Sea (Bagge, 1989; Rudstam et al., 1994) is, at least partially, driven by the availability of prey in specific water layers (Fig. 14b). For example, sprat larvae ascend to surface waters during yolk sac absorption (Wieland and Zuzarte, 1991; Makarchouk and Hinrichsen, 1998). Here they feed during daylight hours and diet composition is largely explained by seasonal available zooplankton composition in the respective layers (Voss et al., 2003).

Gut content analyses of larval sprat indicated that Acartia spp. and $T$. longicornis formed the highest proportions of larval sprat prey items and that Pseudocalanus spp. were absent during the 2002 and 2003 GLOBEC-Germany field campaigns (Dickmann et al., 2007). The absence of the latter further indicates that larval sprat now feed above the thermocline in late spring and summer, where zooplankton taxa of modes I and II are present. A decade prior to these observations (in the late 1980s), Pseudocalanus spp. were more abundant and sprat larvae displayed diel vertical migration, spending the daylight hours in mode IV waters before returning to mode I and II waters at night (Hinrichsen et al., 2010). With the changes in foraging strategy and more strict reliance on foraging in the upper water column, changes in the availability of mode I and II zooplankton are important for larval sprat growth and survival, and can be significantly correlated (e.g., in the case of Acartia spp.) with year class strength (Dickmann, 2005; Voss et al., this volume). The high abundance of Bosmina coregoni maritima in the upper $20 \mathrm{~m}$ makes it a valuable prey item in July/August for later stages of sprat that are, at that point, large enough to ingest them (Dickmann et al., 2007); Bosmina can form nearly $40 \%$ of the diet of larger larvae/post-larvae (Dickmann, 2005). The ontogenetic match between suitable prey in surface waters (mode I and II) for "intermediate" sized larval sprat appears to be one mechanism influencing cohort survival in the Bornholm Basin (Voss et al., this volume).

Cod requires higher salinities for successful development (Wieland and Zuzarte, 1991; Bagge et al., 1994; Wieland et al., 1994) than either herring or sprat. Thus, its early life stages mainly reside in deeper layers where larvae and young juveniles overlap most with Pseudocalanus sp., their principle prey (Hinrichsen et al., 2002; Voss et al., 2003). Decreases in Pseudocalanus would be expected to (and have) exacerbate(d) the potential spatial mismatch between cod and suitable zooplankton prey. Naturally, other dynamics act to reinforce the regime shift from cod to sprat that occurred in the late 1980s (e.g., feeding of clupeids on cod early life stages and eggs: Schnack and Köster, 1994) but the interaction between young cod and mode IV zooplankton is thought to be one critical mechanism. Thus, zooplankton-induced increase in clupeids, that benefit from better conditions in the upper layers, depresses the probability of strong year classes of cod and vice versa (Rudstam et al., 1994).

Changes in habitat utilisation by zooplankton in modes I and II during the summer, well after the spawning periods of cod, sprat and herring, will also have large consequences for predator-prey match-mismatch dynamics for those fishes. For example, adult sprat has a shallow vertical distribution during summer and aggregates at depths deeper than $50 \mathrm{~m}$ during the rest of the year (Köster and Schnack, 1994). Thus, habitats of adult sprat overlap with zooplankton species described by modes III-V. At these depths, sprat prey upon Pseudocalanus spp. and T. longicornis and compete with herring for prey resources (Möllmann and Köster, 2002). The summer shift from a copepod- towards a cladocerandominated zooplankton community decreases the predator-prey overlap for herring residing in deeper waters (Flinkman et al., 1998; Viitasalo et al., 2001).

\section{Outlook}

In many marine systems, clines can structure environmental predator-prey overlaps. For example, both horizontal and vertical gradients in frontal zones determine the distribution of different taxa (e.g. Neuenfeldt, 2002; Escribano et al., 2004). Furthermore, changes in zooplankton composition have coincided with climate-driven changes in hydrography of specific depth strata in systems such as the Barents Sea (Orlova et al., 2002), California Current (Roemmich and McGowan, 1995) and fjord habitats (Gorsky et al., 2000), although observed effects are often not correlated 
with changes in a single physical parameter (Beare et al., 2004). The statistical analysis performed in the present study revealed depth- and seasonal differences in habitats utilised by Baltic Sea zooplankton. The warming and freshening of the Baltic Sea since the 1980s have been correlated with changes in the zooplankton community (Alheit et al., 2005; Möllmann et al., 2009). Prolonged periods of warming of surface waters can cause cascading ecological effects with different impacts expected on species utilising the five different habitat modes identified in this study. The identification of functional groups, such as the five modes of habitat utilisation that we report here for the Bornholm Basin, improves our understanding of how physical processes and factors dictate food web dynamics through changes in predator-prey overlap. The type of analysis performed here allows one to infer species-specific abiotic constraints, habitat utilisation, and spatiotemporal predator-prey overlaps that could be important harbingers of what is expected with future warming and freshening of the Baltic Sea and other areas.

\section{Acknowledgements}

This study would not have been possible without the competent help of colleagues and students during collection and analysis. The authors wish to thank the masters, officers and crew members of the R/V Alexander von Humboldt, R/V Alkor and R/V Heincke. This work was funded by GLOBEC Germany, BMBF 03F0320D.

Additionally we would like to thank two anonymous reviewers who gave valuable suggestions to improve this paper.

\section{References}

Ackefors, H., 1969. Ecological zooplankton investigations in the Baltic Proper 196365. Institute of Marine Research Lysekil, Series Biology Report 18, 1-139.

Alheit, J., Möllmann, C., Dutz, J., Kornilovs, G., Loewe, P., Mohrholz, V., Wasmund, N., 2005. Synchronous ecological regime shifts in the Central Baltic and North Sea in the late 1980s. ICES Journal of Marine Science 62, 1205-1215.

Alldredge, A.L., Robinson, B.H., Fleminger, A., Torres, J.J., King, J.M., Hamner, W.M., 1984. Direct sampling and in situ observation of a persistent copepod aggregation in the mesopelagic zone of the Santa Barbara Basin. Marine Biology 80 (1), 75-81.

Arndt, E.A., Heidecke, D., 1973. Zooplanktonuntersuchungen im Küstenbereich der Mecklenburger Bucht. Wissenschaftliche Zeitschrift der Universität Rostock, Mathematisch Naturwissenschaftliche Reihe 22 (6-7), 599-616.

Arrhenius, F., Hansson, S., 1993. Food consumption of larval, young and adult herring and sprat in the Baltic Sea. Marine Ecology Progress Series 96, 125-137.

Bagge, O., Thurow, F., Steffensen, E., Bay, J., 1994. The Baltic cod. Dana 10, 1-28.

Bagge, O., 1989. A review of investigations of the predation by cod in the Baltic. Rapports et Proces-verbal Conseil Perm. international. Exploration Mer 190, 51 56.

Bakun, A., 2006. Wasp-waist populations and marine ecosystem dynamics: navigating the "predator pit" topographies. Progress in Oceanography 68, 271-288.

Ban, S., Minoda, T., 1989. Seasonal distribution of Eurytemora affinis (Poppe, 1880) (Copepoda, Calanoida) in freshwater Lake Ohnuma. Hokkaido Bulletin Fac. Fish. Hokkaido University 40, 147-153.

Banse, K., 1964. On the vertical distribution of zooplankton in the sea. Progress in Oceanography 2, 53-125.

Barz, K., Hirche, H.J., 2005. Seasonal development of Scyphozoan medusae and the predatory impact of Aurelia aurita on the zooplankton community in the Bornholm Basin (Central Baltic Sea). Marine Biology 147, 465-476.

Barz, K., Hinrichsen, H.-H., Hirche, H.-J., 2006. Scyphozoa in the Bornholm Basin (central Baltic Sea) - the role of advection. Journal of Marine Systems 60, 167176

Beare, D.J., Burns, F., Greig, A., Jones, E.G., Peach, K., Kienzle, M., McKenzie, E., Reid, D.G., 2004. Long-term increases in prevalence of North Sea fishes having southern biogeographic affinities. Marine Ecology Progress Series 284, 269-278.

Bernreuther, M., 2007. Investigations on the Feeding Ecology of Baltic Sea Herring (Clupea harengus L.) and Sprat (Sprattus sprattus L.). PhD Thesis. University of Hamburg, $182 \mathrm{pp}$.

Berrill, N.J., 1950. The tunicate with an account of the British species. Publications of the Ray Society, London 133, 1-354.

Blanner, P., 1982. Composition and seasonal variation of the Zooplankton in the Limfjord (Denmark) during 1973-1974. Ophelia 21 (1), 1-40.

Bonsdorff, E., 2006. Zoobenthic diversity-gradients in the Baltic Sea: continuous post-glacial succession in a stressed ecosystem. Journal of Experimental Marine Biology Ecology 330, 383-391.
Casini, M., Cardinale, M., Arrhenius, F., 2004. Feeding preferences of herring (Clupea harengus) and sprat (Sprattus sprattus) in the Southern Baltic Sea. ICES Journal of Marine Science 61, 1267-1277.

Castellani, C., Robinson, C., Smith, T., Lampitt, R.S., 2005. Temperature affects respiration rate of Oithona similis. Marine Ecology Progress Series 285, 129135.

Chojnacki, J., Drzycimski, I., Siudzinski, K., 1984. The ecological characteristics of the main species of Crustacea in plankton of the southern Baltic. Articles on Biological Productivity of the Baltic Sea, Moscow 2, 148-171.

Colebrook, J.M., John, D.E., Brown, W.W., 1961. Contributions towards a plankton atlas of the north-eastern Atlantic and the North Sea. Part II. Copepoda. Bulletin of Marine Ecology 5, 90-97.

Cushing, D.H., 1975. Marine Ecology and Fisheries. Cambridge University Press, pp. 292.

Cushing, D.H., 1990. Plankton production and year-class strength in fish populations: an update of the match/mismatch hypothesis. Advances in Marine Biology 26, 249-294.

Dagg, M., 1977. Some effects of patchy food environments on copepods. Limnology and Oceanography 22, 99-107.

Dickmann, M., 2005. Feeding Ecology of Sprat (Sprattus sprattus L.) and Sardine (Sardina pilchardus W.) Larvae in the Baltic Sea and North Sea. PhD Thesis, University of Rostock, Germany, pp. 95.

Dickmann, M., Möllmann, C., Voss, R., 2007. Feeding ecology of Central Baltic sprat (Sprattus sprattus L.) larvae in relation to zooplankton dynamics - implications for survival. Marine Ecology Progress Series 342, 277-289.

Dippner, J.W., Vuorinen, I., Daunys, D., Flinkman, J., et al., 2008. Climate related ecosystem change. In: The BACC author team (Eds.), Assessment of Climate Change for the Baltic Sea Basin. Springer Verlag, Berlin, pp. 309-378.

Dippner, J.W., Kornilovs, G., Sidrevics, L., 2000. Long-term variability of mesozooplankton in the Central Baltic Sea. Journal of Marine Systems 25, 2331.

Dutz, J., Mohrholz, V., van Beusekom, J.E.E., 2010. Life cycle and spring phenology of Temora longicornis in the Baltic Sea. Marine Ecology Progress Series 406, 223 238.

Dutz, J., Mohrholz, V., Peters, J., Renz, J., Alheit, J., 2004. A strong impact of winter temperature on spring recruitment of a key copepod species in the Bornholm Basin: potential linkages to climate variability. GLOBEC International Newsletter 10 (1), 13-14.

Engel, M., Hirche, H.J., 2004. Seasonal variability and inter-specific differences in hatching of calanoid copepod resting eggs from sediments of the German Bight (North Sea). Journal of Plankton Research 26 (9), 1083-1093.

Eriksson, S., 1973a. Abundance and composition of zooplanktonon the west coast of Sweden. Zoon 1, 113-123.

Eriksson, S., 1973b. Preliminary Zooplankton investigations in the Öregrund Archipelago (Southwestern Bothnian Sea) during the summer 1970. Zoon 1, 95-111.

Eriksson, S., 1973c. The biology of marine planktonic copepods on the west coast of Sweden. Zoon 1, 37-68.

Eriksson, S., 1974. The occurrence of marine Cladocera on the west coast of Sweden Marine Biology 26, 319-327.

Escribano, R., Daneri, G., Farías, L., Gallardo, V.A., González, H.E., Gutiérrez, D., Lange, C.B., Morales, C.E., Pizarro, O., Ulloa, O., Braun, M., 2004. Biological and chemical consequences of the 1997-1998 El Nino in the Chilean coastal upwelling system: a synthesis. Deep Sea Research II 51, 2389-2411.

Feistel, R., Nausch, G., Mohrholz, V., Łysiak-Pastuszak, E., Seifert, T., Matthäus, W., Krüger, S., Hansen, I.S., 2003a. Warm waters of summer 2002 in the deep Baltic. Oceanologia 45 (4), 571-592.

Feistel, R., Nausch, G., Matthäus, W., Hagen, E., 2003b. Temporal and spatial evolution of the Baltic deep water renewal in spring 2003. Oceanologia 45 (4) 623-642.

Feistel, R., Nausch, G., Matthäus, W., Łysiak-Pastuszak, E., Seifert, T., Hansen, I.S. Mohrholz, V., Krüger, S., Buch, E., Hagen, E., 2004. Background Data to the Exceptionally Warm Inflow into the Baltic Sea in Late Summer of 2002 Meereswissenscahftliche Berichte/Marine Science Report, vol. 58. Institute for Baltic Research, Rostock, Germany, pp. 1-58.

Fenaux, R., Bone, Q., Deibel, D., 1998. Appendicularian distribution and zoogeography. In: Bone, Q. (Ed.) The Biology of Pelagic Tunicates. Oxford University Press, pp. 251-264.

Fisher, R.A., 1936. The utilization of multiple measurements in taxonomic problems Annals of Eugenics 7, 179-188.

Flinkman, J., Aro, E., Vuorinen, I., Viitasalo, M., 1998. Changes in northern Baltic Zooplankton and herring nutrition from 1980's to 1990's: top-down and bottom-up processes at work. Marine Ecology Progress Series 165, 127-136.

Fonselius, F.S., 1970. On the stagnation and recent turnover of the water in the Baltic. Tellus 22 (5), 533-544.

Gieskes, W.W.C., 1970. The Cladocera of the North Atlantic and the North Sea: Biological and Ecological Studies. PhD Thesis, Mc Gill University Montreal Canada.

Gieskes, W.W.C., 1971a. Ecology of the Cladocera of the North Atlantic and the North Sea, 1960-67. Netherland Journal of Sea Research 5, 342-376.

Gieskes, W.W.C., 1971b. The succession of two Podon-species in the North Sea Netherland Journal of Sea Research 5, 377-381.

Gill, A.E., 1982. Atmosphere-Ocean Dynamics. Academic Press, New York, pp. 662

Gorsky, G., Flood, P.R., Youngbluth, M., Picheral, M., Grisoni, J.M., 2000. Zooplankton distribution in four western Norwegian fjords. Estuarine, Coastal and Shel Science 50, 129-135. 
Grabbert, S., Renz, J., Hirche, H.-J., et al., 2010. Species-specific PCR (SS-PCR) discrimination of species of the calanoid copepod Pseudocalanus, $P$. acuspes and P. elongatus in the Baltic and North Sea. Hydrobiologia 652, 289-297.

Graham, W.M., Pages, F., Hamner, W.M., 2001. A physical context for gelatinous zooplankton aggregations: a review. Hydrobiologia 451, 199-212.

Gran, H.H., Hentschel, E., Russell, F.S., 1936. Handliste zur Bestimmung nordischen Planktons. Rapports et Proces-Verbaux des reunions, C(III), 15-20.

Gröndahl, F., Hernroth, L., 1987. Release and growth of Cyanea capillata (L.) ephyrae in the Gullmar Fjord, western Sweden. Journal of Experimental Marine Biology and Ecology 106, 91-101.

Gurney, R., 1931. British Fresh Water Copepoda I. General Part and Calanoida. The Ray Society, London, pp. 1-238.

Hair, J.F., Anderson, Tatham., Black, B., 1998. Multivariate Data Analysis, fifth edition. Prentice Hall Pearson Education, London.

Halsband-Lenk, C., Hirche, H.-J., Carlotti, F., 2002. Temperature impact on reproduction and development of congener copepod populations. Journal of Experimental Marine Biology and Ecology 271, 121-153.

Hansen, F.C., Möllmann, C., Schütz, U., Hinrichsen, H.H., 2004. Spatio-temporal distribution of Oithona similis in the Bornholm Basin (Central Baltic Sea). Journal of Plankton Research 26 (6), 659-668.

Hay, S.J., Kiørboe, T., Matthews, A., 1991. Zooplankton biomass and production in the North Sea during the Autumn Circulation Experiment, October 1987-March 1988. Continental Shelf Research 11 (12), 1453-1476.

Hernroth, L., Ackefors, H., 1979. The Zooplankton of the Baltic Proper. Report Fishery Board of Sweden, Institute Marine Research 2, 1-60.

Hinrichsen, H.H., St. John, M.A., Lehmann, A., MacKenzie, B.R., Köster, F., 2002 Resolving the impact of physical forcing variations on the eastern Baltic cod spawning environment. Journal of Marine Systems 32, 281-294.

Hinrichsen, H.-H., Peck, M.A., Schmidt, J., Huwer, B., Voss, R., 2010. Decadal changes in the diel vertical migration behavior of Baltic sprat larvae: causes and consequences. Limnology and Oceanography 55 (4), 1484-1498.

Hinrichsen, H.H., Kühn, W., Peck, M.A., Voss. R., this volume. The impact of physical and biological factors on the drift and spatial distribution of larval sprat: A comparison of the Baltic and North Seas. Progress in Oceanography.

Hirche, H.J., 1992. Egg production of Eurytemora affinis - effect of k-strategy. Estuarine, Coastal and Shelf Science 35, 395-407.

Holmborn, T., Goetze, E., Põllüü, M., Põllumä, A., 2011. Genetic species identification and low genetic diversity in Pseudocalanus acuspes of the Baltic Sea. Journal of Plankton Research 33, 507-515.

Holste, L., St. John, M.A., Peck, M.A., 2009. The effects of temperature and salinity on reproductive success of Temora longicornis in the Baltic Sea: a copepod coping with a tough situation. Marine Biology 156, 527-540.

Holt, R.D., Polis, G.A., 1997. A theoretical framework for intraguild predation. The American Naturalist 149, 745-764.

Houde, E.D., 2008. Emerging from Hjort's Shadow. Journal of the Northwest Atlantic Fisheries Science 41, 53-70.

Janas, U., Witek, Z., 1993. The occurrence of medusae in the Baltic and their importance in the ecosystem, with special emphasis on Aurelia aurita. Oceanologia 34, 69-84.

Jespersen, P., 1940. Non-parasitic copepoda. Zoology of Iceland III (33), 1-116

Jespersen, P., 1949. Investigations on the occurrence and quantity of holoplankton animals in the Isefjord, 1940-45. Meddr Kommn Danm. Fisk.- og Harvunders, Plankton 5(3), 1-18.

Jørgensen, H.B.H., Hansen, M.M., Bekkevold, D., Ruzzante, D.E., Loeschcke, V., 2005. Marine landscapes and population genetic structure of herring (Clupea harengus L.) in the Baltic Sea. Molecular Ecology 14, 3219-3234.

Kideys, A.E., Romanova, Z., 2001. Distribution of gelatinous macrozooplankton in the southern Black Sea during 1996-1999. Marine Biology 139, 535-547.

Köster, F.W., Schnack, D., 1994. The role of predation on early life stages of cod in the Baltic. Dana 10, 179-201.

Krause, M., Dippner, J.W., Beil, J., 1995. A review of hydrographic controls on the distribution of zooplankton biomass and species in the North Sea with particular reference to a survey conducted in January-March 1987. Progress in Oceanography 35, 81-152.

Laine, A.O., Sandler, H., Andersin, A.B., Stigzelius, J., 1997. Long term changes of macrozoobenthos in the Eastern Gotland Basin and the Gulf of Finland (Baltic Sea) in relation to the hydrographical regime. Journal of Sea Research 38, 135159.

Lance, J., 1962. Effects of water of reduced salinity on the vertical migration of zooplankton. Journal of the Marine Biological Association UK 42, 131-154.

Lande, R., Wood, M., 1987. Suspension times of particles in the upper ocean. Deep Sea Research 34, 61-72.

Larsen, J.B., Frischer, M.E., Ockelmann, K.W., Rasmussen, L.J., Hansen, B.W., 2007 Temporal occurrence of planktotrophic bivalve larvae identified morphologically and by single step nested multiplex PCR. Journal of Plankton Research 29, 423-436.

Launiainen, J., Matthaeus, W., Fonselius, S., Francke, E., 1987. In: Lassig, J. (Ed.) Hydrography (Baltic Sea). University Helsinki, Department Geophys, Helsinki, Finland.

Lehmann, A., Krauss, W., Hinrichsen, H.H., 2002. Effects of remote and local forcing on circulation and upwelling in the Baltic Sea. Tellus 54A, 299-316.

Leppäkoski, E., 1971. Benthic recolonization of the Bornholm Basin (Southern Baltic) in 1969-71. Thalassia Jugoslavica 7 (1), 171-179.

Leppäkoski, E., 1975. Macrobentic fauna as indicator of ozeanization in the southern Baltic. Merentutkimuslait Julk Havsforskningsinstitut Skr 239, 280-288.
Lieder, U., 1983. Revision of the genus Bosmina (Baird, 1845) (Crustacea, Cladocera). International Rev der Gesamten Hydrobiologie 68, 121-139.

Lindquist, A., 1959. Studien über das Zooplankton der Bottensee. II Zur Verbreitung und Zusammensetzung des Zooplanktons. Institute Marine Research, Lysekil, Series Biology 11, 1-136.

Lischka, M., 1999: Abundanz, Verteilung und Nahrungsökologie von Scyphomedusen in der zentralen Ostsee. Diploma Thesis, Kiel University, Kiel, pp. 91.

Lohmann, H., 1899. Das Gehäuse der Appendicularien, sein Bau, seine Funktion und seine Entstehung. Schriften des Naturwissenschaftlichen Vereins für Schleswig Holstein 11 (2), 347-407.

Longhurst, A.R., Harrison, W.G., 1989. The biological pump: profiles of plankton production and consumption in the upper ocean. Progress in Oceanography 22, 47-123.

MacIntyre, S., Alldredge, A.L., Gotschalk, C.C., 1995. Accumulation of marine snow at density discontinuities in the water column. Limol Oceanography 40, 449-468.

Makarchouk, A., Hinrichsen, H.H., 1998. The Vertical Distribution of Ichtyoplankton in Relation to the Hydrographic Conditions in the Eastern Baltic. ICES, CM 1998/ $\mathrm{R}: 11$.

Mankowski, W., 1951. Biological changes in the Baltic during the last fifty years. Prace MIR w Gdyni 6, 96-118.

Margonski, P., Horbowa, K., 1995. Vertical distribution of cod eggs and medusae in the Bornholm basin. Medd Havsfiskelab Lysekil 327, 7-17.

Matthäus, W., 1995. Natural variability and human impacts reflected in long-Term changes in the Baltic deep water conditions - a brief review. Deutsche Hydrographische Zeitschrift 47 (1), 47-65.

Matthäus, W., Frank, H., 1992. Characteristics of major baltic inflows - a statistical analysis. Continental Shelf Research 12 (12), 1375-1400.

Matthäus, W., Schinke, H., 1994. Mean atmospheric circulation patterns associated with major Baltic inflows. Deutsche Hydrographische Zeitschrift 46, 321-338.

Meeus, J., 1994. Astronomische Algorithmen, second ed. Johann Ambrosius Barth Verlag. ISBN 0-943396-35.

Möller, H., 1980a. A summer survey of large zooplankton, particularly Scyphomedusae, in North Sea and Baltic. Meeresforschung 28, 61-68.

Möller, H., 1980b. Population Dynamics of Aurelia aurita medusae in Kiel Bight, Germany (FRG). Marine Biology 60, 123-128.

Möllmann, C., Diekmann, R., Müller-Karulis, B., Kornilovs, G., Plikshs, M., Axe, P., 2009. Reorganization of a large marine ecosystem due to atmospheric and anthropogenic pressure: a discontinuous regime shift in the Central Baltic Sea. Global Change Biology 15, 1377-1393.

Möllmann, C., Kornilovs, G., Fetter, M., Köster, F.W., Hinrichsen, H.-H., 2003. The marine copepod, Pseudocalanus elongatus, as a mediator between climate variability and fisheries in the Central Baltic Sea. Fisheries Oceanography 12 (4/ 5), 360-368.

Möllmann, C., Köster, F.W., 2002. Population dynamics of calanoid copepods and the implications of their predation by clupeid fish in the Central Baltic Sea. Journal of Plankton Research 24 (10), 959-977.

Möllmann, C., Kornilovs, G., Sidrevics, L., 2000. Long-term dynamics of main mesozooplankton species in the central Baltic Sea. Journal of Plankton Research 22 (11), 2015-2038

Mohrholz, V., Dutz, J., Kraus, G., 2006. The impact of exceptional warm summer inflow events on the environmental conditions in the Bornholm Basin. Journal of Marine Systems 60, 285-301.

Mohrholz, V., Schuffenhauer, I., http://www.ifm.zmaw.de/globec/pub/ gg_Poster2004_VMohrholz.pdf, 2004. The Exceptional Inflow 2002: Climatological Aspects.

Mutlu, E., Bingel, F., 1999. Distribution and abundance of ctenophores and their zooplankton food in the Black Sea. Marine Biology 135, 589-601.

Neuenfeldt, S., 2002. The influence of oxygen saturation on the distributional overlap of predator (cod, Gadus morhua) and prey (herring, Clupea harengus) in the Bornholm Basin of the Baltic Sea. Fisheries Oceanography 11 (1), 11-17.

Nielsen, T.G., Sabatini, M., 1996. Role of cyclopoid copepods Oithona spp. in the North Sea plankton communities. Marine Ecology Progress Series 139, 7993.

Ojaveer, E., Lumberg, A., Ojeveer, H., 1998. Highlights of zooplankton dynamics in Estonian waters (Baltic Sea). ICES Journal of Marine Science 55, 748-755.

Orlova, E.L., Boitsov, V.D., Nesterova, V.N., Ushakov, N.G., 2002. Composition and distribution of copepods, a major prey of capelin in the central Barents Sea, in moderate and warm years. ICES Journal of Marine Science 59, 1053-1061.

Peck, M.A., Baumann, H., Bernreuther, M., Clemmesen, C., Herrmann, J.-P., Huwer, B., Kanstinger, P., Petereit, C., Temming, A., Voss, R., this volume. The ecophysiology of Sprattus sprattus in the Baltic and North Seas. Progress in Oceanography. http://dx.doi.org/10.1016/j.pocean.2012.04.013.

Peters, J., 2006. Lipids in key copepod species of the Baltic Sea and North Sea implications for life cycles, trophodynamics and food quality. Dissertation, University of Bremen, 159 pp.

Peters, J., Dutz, J., Hagen, W., 2007. Role of essential fatty acids on the reproductive success of the copepod Temora longicornis in the North Sea. Marine Ecology Progress Series 341, 153-163.

Peters, J., Dutz, J., Hagen, W., in press. Trophodynamics and life cycle strategies of the copepods Temora longicornis and Acartia longiremis in the Central Baltic Sea. Marine Ecology Progress Series.

Peters, J., Renz, J., van Beusekom, J., Boersma, M., Hagen, W., 2006. Trophodynamics and seasonal cycle of the copepod Pseudocalanus acuspes in the Central Baltic Sea (Bornholm Basin): evidence from lipid composition. Marine Biology 149, 1417-1429. 
Postel, L., 1996. In: Rheinheimer (Ed.), Meereskunde der Ostsee. Springer Verlag, Berlin, Heidelberg, New York.

Pörtner, H.O., 2010. Oxygen and capacity limitation of thermal tolerance: a matrix for integrating climate related stressors in marine ecosystems. Journal of Experimental Biology 213, 881-893.

Purasjoki, K.J., 1958. Zur Biologie der Brackwasserkladozere Bosmina coregoni maritima. Annales Zoologici Societatis Zoologicae-Botanicae Fennicae 'Vanamo' 19 (2), 1-117.

Rae, K.M., Fraser, J.H., 1941. Continuous Plankton Records. The copepods of the southern North Sea, 1932-37. Hull Bulletins of Marine Ecology 1, 171-238.

Rae, K.M., Rees, C.B., 1947. Continuous plankton records: the Copepoda in the North Sea, 1938-1939. Hull Bulletins of Marine Ecology 2 (11), 95-132.

Ramner, W., 1930. Crustacea, Phyllopoda. Tierwelt in Nord und Ostsee, X, pp. 32.

Rasmussen, E., 1973. Systematics and ecology of the Isefjord marine fauna (Denmark). Ophelia 11, 1-507.

Rees, C.B., 1954. Continuous plankton records: the distribution of Lamellibranch larvae in the North Sea, 1950-51. Hull Bulletins of Marine Ecology 4 (27), 2146.

Renz, J., Hirche, H.J., 2006. Life cycle of Pseudocalanus acuspes Giesbrecht (Copepoda, Calanoida) in the Central Baltic Sea: seasonal and spatial distribution. Marine Biology 148, 567-580.

Renz, J., Peters, J., Hirche, H.-J., 2007. Life cycle of Pseudocalanus acuspes Giesbrecht (Copepoda, Calanoida) in the Central Baltic Sea: II. Reproduction, growth and secondary production. Marine Biology 151, 515-527.

Roemmich, D., McGowan, J., 1995. Climatic warming and the decline of zooplankton in the California Current. Science 267, 1324-1326.

Root, R.B., 1967. The niche exploitation pattern of the blue-gray gnatcatcher. Ecological Monographs 37, 317-350.

Rudstam, L.G., Aneer, G., Hilden, M., 1994. Top-down control in the pelagic Baltic ecosystem. Dana 10, 105-129.

Schmidt, J., 2006. Small and Meso-Scale Distribution Patterns of Key Copepod Species in the Central Baltic Sea and Their Relevance for Larval Fish Survival. PhD Thesis University, Kiel, Germany, 89 pp.

Schmidt, J.O., Möllmann, C., Temming, A., Herrmann, J.P., Flöter, J., Sell, A., St. John, M., 2003. Unusual water mass advection affected Central Baltic key species 2: Pseudocalanus and the winter inflow. International GLOBEC Newsletter 9 (2), 28-29.

Schlitzer, R., http://www.awi.de/GEO/ODV (case sensitive), 2004. Ocean Data View.

Schnack, F.W., Köster, D., 1994. The role of predation on early life stages of cod in the Baltic. Dana 10,179-201.

Schulz, J., http://www.awi.de/Software/OST (case sensitive), 2005. Ocean Sneaker's Tool.

Schulz, J., Hirche, H.-J., 2007. Living below the halocline: strategies of deep-living species in the highly stratified brackish Bornholm Basin (central Baltic Basin). Journal of Plankton Research 29 (10), 881-894.
Schulz, J., Möllmann, C., Hirche, H.J., 2007. Vertical zonation of the zooplankton community in the Central Baltic Sea in relation to hydrographic stratification as revealed by Multivariate Discriminant Function- and Canonical Analysis. Journal of Marine Systems 67, 47-58.

Steele, J.H., 1989. The ocean landscape. Landscape Ecology 3, 185-192.

Taylor, D.J., Ishikane, C.R., Haney, R.A., 2002. The systematics of Holarctic bosminids and a revision that reconciles molecular and morphological evolution. Limnology and Oceanography 47 (5), 1486-1495.

Telesh, I., Postel, L., Heerkloss, R., Mironova, E., Skarlato, S., 2009. Zooplankton of the Open Baltic Sea: Extended Atlas. Atlas. BMB Publication No. 21 - Meereswiss. Ber., Warnemünde, 76, 1-290. ISSN 0939-396X.

Titelman, J., Fiksen, Ø., 2004. Ontogenetic vertical distribution patterns in small copepods: field observations and model predictions. Marine Ecology Progress Series 284, 49-63.

Vallin, L., Nissling, A., 2000. Maternal effects on egg size and egg buoyancy of Baltic cod, Gadus morhua - Implications for stock structure effects on recruitment. Fish Research 49, 21-37.

Viitasalo, M., Flinkman, J., Viherluoto, M., 2001. Zooplanktivory in the Baltic Sea: a comparison of prey selectivity by Clupea harengus and Mysis mixta, with reference to prey escape reactions. Marine Ecology Progress Series 216, 191 200.

Viitasalo, M., Koski, M., Pellikka, K., Johansson, S., 1995. Seasonal and long-term variations in the body size of planktonic copepods in the northern Baltic Sea. Marine Biology 123, 241-250.

Vinogradov, M.E., Flint, M.V., Shushkina, E.A., 1985. Vertical distribution of mesoplankton in the open area of the Black Sea. Marine Biology 89, 95-107.

Voss, R., Köster, F.W., Dickmann, M., 2003. Comparing the feeding habits of cooccurring sprat (Sprattus sprattus) and cod (Gadus morhua) larvae in the Bornholm Basin, Baltic Sea. Fisheries Research 63, 97-111.

Voss, R., Peck, M.A., Hinrichsen, H.-H., Clemmesen, C., Baumann, H., Stepputtis, D., Berneuther, M., Schmidt, J.O., Temming, A., Köster, F.W., this volume. Recruitment processes in Baltic sprat - a re-evaluation of GLOBEC-Germany hypotheses. Progress in Oceanography.

Vuorinen, I., Haenninen, J., Viitasalo, M., Helminen, U., Kuosa, H., 1998. Proportion of copepod biomass declines with decreasing salinity in the Baltic Sea. ICES Journal of Marine Science 55, 767-774.

Wieland, K., Waller, U., Schnack, D., 1994. Development of Baltic cod eggs at different levels of temperature and oxygen content. Dana 10, 163-177.

Wieland, K., Zuzarte, F., 1991. Vertical Distribution of Cod and Sprat Eggs and Larvae in the Bornholm Basin (Baltic Sea) 1987-1990. ICES CM1991/J:37.

Young, K.V., Dower, J.E., Pepin, P., 2009. A hierarchical analysis of the spatial distribution of larval fish prey. Journal of Plankton Research 31 (6), 687-700. 